\title{
Regulator of Calcineurin 1 Modulates Expression of Innate Anxiety and Anxiogenic Responses to Selective Serotonin Reuptake Inhibitor Treatment
}

\author{
Charles A. Hoeffer, ${ }^{1,2,3 *}$ Helen Wong, ${ }^{2,3 *}$ Peter Cain, ${ }^{4}$ Josien Levenga, ${ }^{1,2}$ Kiriana K. Cowansage, ${ }^{3}$ Yoon Choi, ${ }^{1,2}$ \\ Camille Davy, ${ }^{1,2}$ Neil Majmundar, ${ }^{3}$ D. Randy McMillan, ${ }^{5}$ Beverly A. Rothermel, ${ }^{5}$ and Eric Klann ${ }^{3}$ \\ ${ }^{1}$ Department of Neuroscience \& Physiology, ${ }^{2}$ Druckenmiller Neuroscience Institute, New York University School of Medicine, Langone Medical Center, \\ New York, New York 10016, ${ }^{3}$ Center for Neural Science, New York University, New York, New York 10003, ${ }^{4}$ Department of Psychology, Excelsior College, \\ Albany, New York 12203, and 5Departments of Internal Medicine and Molecular Biology, University of Texas Southwestern Medical Center, Dallas, Texas \\ 75390
}

Regulator of calcineurin 1 (RCAN1) controls the activity of calcium/calmodulin-dependent phosphatase calcineurin (CaN), which has been implicated in human anxiety disorders. Previously, we reported that RCAN1 functioned as an inhibitor of CaN activity in the brain. However, we now find enhanced phosphorylation of a CaN substrate, cAMP response element-binding protein (CREB), in the brains of Rcan1 knock-out (KO) mice. Consistent with enhanced CREB activation, we also observe enhanced expression of a CREB transcriptional target, brain-derived neurotrophic factor (BDNF) in Rcan1 K0 mice. We also discovered that RCAN1 deletion or blockade of RCAN1-CaN interaction reduced $\mathrm{CaN}$ and protein phosphatase-1 localization to nuclear-enriched protein fractions and promoted CREB activation. Because of the potential links between CREB, BDNF, and anxiety, we examined the role of RCAN1 in the expression of innate anxiety. Rcan1 KO mice displayed reduced anxiety in several tests of unconditioned anxiety. Acute pharmacological inhibition of CaN rescued these deficits while transgenic overexpression of human $R C A N 1$ increased anxiety. Finally, we found that Rcan 1 KO mice lacked the early anxiogenic response to the selective serotonin reuptake inhibitor (SSRI) fluoxetine and had improved latency for its therapeutic anxiolytic effects. Together, our study suggests that RCAN1 plays an important role in the expression of anxiety-related and SSRI-related behaviors through CaN-dependent signaling pathways. These results identify RCAN1 as a mediator of innate emotional states and possible therapeutic target for anxiety.

\section{Introduction}

Anxiety, an adaptive response to stress, can at low levels enhance performance and enable escape from danger. Excessive or inappropriate anxiety, however, results in pathological impairment of normal everyday tasks. Pathological anxiety is among the most prevalent comorbid conditions in psychiatric disorders. Anxiety is frequently distinguished from fear by its lack of specificity and its spontaneity in the absence of an

Received July 23, 2012; revised Sept. 14, 2013; accepted Sept. 17, 2013.

Author contributions: C.A.H., H.W., K.K.C., and B.A.R. designed research; C.A.H., H.W., P.C., J.L., K.K.C., Y.C., C.D., N.M., and D.R.M. performed research; D.R.M. contributed unpublished reagents/analytic tools; C.A.H., H.W., P.C., J.L., and C.D. analyzed data; C.A.H., H.W., P.C., K.K.C., B.A.R., and E.K. wrote the paper.

This work was supported by the Alzheimer's Association (Grant 12-258900; (.A.H.), Simons Foundation (C.A.H.), and National Institutes of Health (National Institute of Mental Health and National Institute of Neurological Disorders and Stroke Grants NS034007 and NS047384, E.K.; National Institutes of Health Grants HL097768 and HL072016, B.A.R.). This work was also supported by the technical assistance of the New York University Office of Veterinary Services. We thank M. Chao for useful discussions and reading the manuscript. We thank E. Nestler and T. Abel for providing CREB knockdown tissues. We also thank Marie Monfils, Chloe Steindam, and Christi Hull for excellent technical assistance.

${ }^{*}$ C.A.H. and H.W. contributed equally to this work.

The authors declare no competing financial interests.

Correspondence should be addressed to Charles A. Hoeffer, Druckenmiller Neuroscience Institute, New York University School of Medicine, 550 First Ave., SRB 610, New York, NY 10016. E-mail: charles.hoeffer@gmail.com.

DOI:10.1523/JNEUROSCI.3513-12.2013

Copyright $\odot 2013$ the authors $\quad 0270-6474 / 13 / 3316930-15 \$ 15.00 / 0$ imminent threat (Duman and Duman, 2005). To identify the neurobiological correlates of anxiety, genetic and pharmacological manipulations have been used to study anxiety-related behaviors in rodents (Gould, 2009). Normal mice display a marked preference for "unexposed" areas. The frequency and duration that mice explore exposed areas are used as measures of anxiety (File et al., 1990).

Little is known about the molecular substrates for anxietyrelated behavior, but studies have implicated neuronal signaling pathways that use calcium. Calcineurin (CaN) is a calcium/ calmodulin-dependent serine/threonine phosphatase with numerous neuronal functions, including the expression of anxiety (Manji et al., 2003; Bahi et al., 2009; Baumgärtel and Mansuy, 2012). In addition to calcium/calmodulin, several regulatory proteins controlling CaN activity have been identified. One such protein is regulator of calcineurin 1 (RCAN1), which can function as both an inhibitor and facilitator of CaN activity, depending on cellular context (Kingsbury and Cunningham, 2000; Vega et al., 2002; Hilioti et al., 2004; Sanna et al., 2006). RCAN1 binds $\mathrm{CaN}$ and inhibits its catalytic activity (Rothermel et al., 2000; Chan et al., 2005). In addition, RCAN1 can inhibit CaN by competing with substrates for the active site (Martínez-Martínez et al., 2009). Conversely, RCAN1 can also mediate CaN interaction 
with other proteins that facilitate CaN activity (Sanna et al., 2006; Liu et al., 2009).

cAMP response element-binding protein (CREB) is another calcium-regulated protein linked to anxiety (Pandey et al., 1999; Barrot et al., 2002; Carlezon et al., 2005; Wallace et al., 2009). CREB is a transcription factor that is regulated by reversible phosphorylation at serine-133 (S133) through several kinases and phosphatases, including CaN (Bito et al., 1996). A major target of CREB activity is brain-derived neurotrophic factor (BDNF; Tao et al., 1998). BDNF plays a prominent role in anxiety-related behaviors in rodents (Pandey et al., 1999; Rios et al., 2001; Chen et al., 2006) and psychiatric patients (Jiang et al., 2005; Molendijk et al., 2012). CaN regulation of these two proteins may control the manifestation of anxiety.

$\mathrm{CaN}$ has been associated with psychiatric disorders (Gerber et al., 2003) and is influenced by such medications as selective serotonin reuptake inhibitors (SSRIs) used to treat anxiety disorders (Crozatier et al., 2007; Rushlow et al., 2009). The connection between $\mathrm{CaN}$ and anxiety led us to investigate CREB activity and anxiety-related behaviors in Rcan1 knock-out (KO) mice. We found that (1) phosphorylation of CREB and protein levels of the CREB-dependent gene $B d n f$ were enhanced in the brains of Rcan1 KO mice; (2) RCAN1 interaction with CaN regulated nuclear phosphatase localization; (3) Rcan1 KO mice displayed lower unconditioned anxiety, which was reversed by pharmacological inhibition of $\mathrm{CaN}$; and (4) consistent with an inhibitory role of RCAN1 on CaN in the manifestation of anxiety, Rcan $1 \mathrm{KO}$ mice were resistant to the acute anxiogenic phase of SSRI treatment using fluoxetine (Belzung et al., 2001). Together these data provide evidence for RCAN1 function in the molecular signaling pathways that regulate innate anxiety.

\section{Materials and Methods}

Animals. Age-matched male littermates from the same genetic background (depending on strain) were used for all studies. Rcan1 ${ }^{-/-}(\mathrm{KO})$ mice (Vega et al., 2003) or Cre-driven RCAN1-overexpressing transgenic mice carrying human RCAN1 protein at high (Tg1) or low (Tgla) levels (Oh et al., 2005) were used to manipulate RCAN1 expression. Rcan1 KO mice have an exon deletion that eliminates RCAN1 protein expression (Hoeffer et al., 2007). The Rcan1 KO mice used in this study were backcrossed from a mixed C57BL/6x129 background (Vega et al., 2003) to C57BL/6 for seven generations before testing. Rcan $1^{+/+}$littermates were used as wild-type (WT) controls for these mice. Nse-Cre ${ }^{+/-} \mathrm{Tg}$-CAT::RCAN1 (Nse$R C A N 1^{T g 1}$ or Nse-RCAN1 ${ }^{T g 1 a}$ ) mice overexpress RCAN1 (Oh et al., 2005) following activation with Cre under a neuron-specific enolase (Nse) driver (Forss-Petter et al., 1990). CamkII $\alpha$-Cre ${ }^{+/-} \mathrm{Tg}$-CAT::RCAN1 (CamkII $\alpha$ $R C A N 1^{T g 1}$ or CamkII $\left.\alpha-R C A N 1^{T g 1 a}\right)$ overexpress RCAN1 following activation with Cre under a calcium/calmodulin-dependent kinase II $\alpha$ (CamkII $\alpha$ ) driver (Tsien et al., 1996). The transgene has been crossed into the same genetic background as the driver lines for 5-7 generations before testing. Littermates carrying the RCAN1 transgene but lacking Cre constructs were used as controls for $N s e-R C A N 1^{T g}$ or CamkII $\alpha-R C A N 1^{T g}$ mice and referred to as "WT." RCAN1 expression was confirmed using immunoblotting. Mice were maintained on a $12 \mathrm{~h} \mathrm{light/dark} \mathrm{schedule} \mathrm{with} \mathrm{food} \mathrm{and} \mathrm{water} \mathrm{available}$ ad libitum and tested at $8-20$ weeks of age. All procedures were approved by the New York University Institutional Animal Care and Use Committee in compliance with the National Institutes of Health Guide for the Care and Use of Laboratory Animals.

Order of behavioral tests and cohorts used. The order of behavioral tests and cohorts used was as follows: Rcan1 KO: Cohorts 1, 3: open-field arena (OFA; $27 \mathrm{~cm}^{2}$ ), elevated plus maze (EPM); Cohort 2: OFA (27 $\mathrm{cm}^{2}$ ), time bin experiment (see Fig. 3D), EPM; Cohorts 4, 6: OFA, EPM FK506 experiments; Cohort 5: handling habituation only, prepulse inhibition (PPI); Cohorts 7-10: OFA, EPM fluoxetine experiments; Cohort 11: OFA $\left(40 \mathrm{~cm}^{2}\right)$. Cohorts 12, 13 (cannulation): EPM cyclosporine-A (CsA) experiments. Nse-RCAN1 ${ }^{T g 1}$ : Cohorts 1-2:
OFA, EPM. Nse-RCAN1 ${ }^{\text {Tgla }}$ : Cohorts 1-4: OFA, EPM, PPI. CamkII $\alpha-$ $R C A N 1^{T g 1}$ : Cohorts 1-4: OFA, EPM. CamkII $\alpha-R C A N 1^{T g 1 a}$ : Cohorts 1-2: OFA, EPM, PPI.

OFA. Movement was measured in one of two acoustically isolated test arenas $\left(27.3 \times 27.3 \mathrm{~cm}^{2}\right.$ or $40 \times 40 \mathrm{~cm}^{2}$; Med Associates $)$. Arena activity of the mouse over $15 \mathrm{~min}$ was measured by infrared light beam breaks and recorded by computer for later analysis. Illumination levels during testing were maintained at 60 lux.

EPM. A white 39-cm-arm-length EPM arena was used for testing (Columbus Instruments). Mice were placed in the center zone of the maze and activity was recorded for $5 \mathrm{~min}$ by video camera (LTC 0335, Bosch). Subject movements were analyzed with Ethovision-XT (Noldus). Illumination levels during testing were maintained at 195 lux with $55 \mathrm{~dB}$ white noise in the background.

PPI. PPI was determined using SR-LAB startle response chambers (San Diego Instruments). The startle response to an acoustic stimulus was measured in the presence of a $65 \mathrm{~dB}$ white noise background following a 5 min acclimation period. Each session consisted of a randomized block design of 42 trials that presented a 20 ms prepulse of $74,78,82,86$, or $90 \mathrm{~dB}$ followed $100 \mathrm{~ms}$ later by either a $40 \mathrm{~ms} 120 \mathrm{~dB}$ startle pulse or no pulse (null). The intertrial interval for prepulse presentations averaged $15 \mathrm{~s}$ and was pseudorandomized.

Cannula implantation. Animals were anesthetized with 5\% isoflurane (Aerrane, Baxter Healthcare) in $\mathrm{O}_{2}$ (Matrx VIP 3000, Midmark) and maintained with a $1 \%$ isoflurane $/ \mathrm{O}_{2}$ mixture on a stereotaxic apparatus (Kopf Instruments) for the duration of surgery. Twenty-two gauge cannulae (Plastics One) were inserted bilaterally in the ventricles at the following bregma coordinates: anteroposterior, $-0.22 \mathrm{~mm}$; mediolateral, $\pm 1.0 \mathrm{~mm}$; dorsoventral, $-2.25 \mathrm{~mm}$. The cannulae were secured to the skull with acrylic dental cement. Mice were allowed to recover 5-7 d postsurgery before behavior experiments.

Drug administration. For FK506 experiments, mice were injected as previously described (Hoeffer et al., 2007). For dipyridamole experiments, hippocampal slices were prepared as described previously (Hoeffer et al., 2007). Following a $60 \mathrm{~min}$ recovery at $32^{\circ} \mathrm{C}$, slices were treated either with dipyridamole diluted from a DMSO stock solution in artificial CSF (ACSF) or with vehicle at a final DMSO concentration of $0.1 \%$. For CsA experiments, $3 \mu \mathrm{l}$ of vehicle only (ASCF) or vehicle containing CsA $(0.625 \mathrm{nmol} / \mathrm{g})$ were infused into each ventricle simultaneously $(6 \mu \mathrm{l}$ total) via cannula at a rate of $0.3 \mu \mathrm{l} / \mathrm{min}$ (PHD 2000, Harvard Apparatus). Drug was allowed to dissipate for $5 \mathrm{~min}$ before injectors were removed. Animals were returned to holding cages for $60 \mathrm{~min}$ postinfusion in the testing room before behavior experiments. For fluoxetine experiments, mice were injected intraperitoneally with vehicle only $(0.9 \%$ saline) or vehicle containing fluoxetine $(10 \mathrm{mg} / \mathrm{kg}$; Sigma-Aldrich). For chronic fluoxetine drug administration, mice were injected at the same time everyday using alternating injection sides. On EPM testing days (1, $3,15)$, testing was performed before drug injection.

CaN activity assay. Total protein lysate was prepared from coronal slices containing prefrontal cortex (PFC) for performing CaN phosphatase activity measurements as previously described (Hoeffer et al., 2007). PFC slices or lysates were incubated with pharmacological phosphatase inhibitors and soluble peptide inhibitors specific for CaN (autoinhibitory peptide $20 \mathrm{~mm}$, Tocris Bioscience). Phosphatase activity was then determined using a commercially available kit according to manufacturer's instructions (EnzChek, Life Technologies) and measured on a microplate reader (Synergy, BioTek Instruments).

Immunohistochemistry. Tissues from brain regions were isolated and soluble protein extracts prepared as previously described (Hoeffer et al., 2007). For cellular fractionation, PFC tissue from three mice were pooled, weighed, and homogenized on ice in 5-10 volumes of extraction buffer using a Kontes Dounce tissue grinder as described by Hoeffer et al., (2007). The homogenate was centrifuged for $3 \mathrm{~min}$ at $800 \times g, 4^{\circ} \mathrm{C}$. The nuclear-enriched pellet (P1) was washed three times with extraction buffer. Proteins were resolved on SDS-polyacrylamide gels and blotted on PVDF membranes using standard techniques. Membranes were incubated for $24-48 \mathrm{~h}$ at $4^{\circ} \mathrm{C}$ with primary antibodies against phosphoCREB S133 (1:1000; Millipore), total CREB (1:1000; Bethyl Laboratories), Lamin A/C (1:1000; Cell Signaling Technology), CaN A 
(1:10,000; Abcam), BDNF (1:500; Abcam), protein phosphatase-1 (PP1, 1:200; Abbiotec), RCAN1 (1:500; B. Rothermel), GAPDH (1:5000; Cell Signaling Technology), or histone H3 (1:10,000; Cell Signaling Technology). Primaries were detected with HRP-conjugated goat anti-rabbit or anti-mouse secondary antibodies (1:5000; Promega) and visualized with ECL (GE Healthcare) on a Kodak 4000MM or GE LAS4000 imaging system.

mRNA extraction, cDNA preparation, semiquantitative PCR. Tissue from freshly dissected mouse brains was flash frozen and pulverized for mRNA extraction using Trizol (Invitrogen). cDNA was prepared using oligo-DT primers and Omniscript (Qiagen). Equal amounts of cDNA were used as template for target $(B d n f)$ and control $(\beta$-actin) semiquantitative PCR. Primer sequences used for BDNF were obtained from Martinowich et al. (2003). PCR products were visualized using agarose gel electrophoresis and standard nucleotide staining.

Statistics. Student's $t$ test, ANOVA, or nonparametric tests (i.e., Kruskal-Wallace or Mann-Whitney) were applied to behavior and biochemistry experiments as appropriate. The use of parametric or nonparametric tests was determined with the Shapiro-Wilk test for normality. Significant main effects or interactions were followed by post hoc testing as appropriate. Outliers were excluded using Grubb's method. All statistical tests are two-tailed with significance level set at 0.05 . Data on graphs represent mean \pm SEM. Statistical analysis was performed using SPSS software.

\section{Results}

\section{Loss of Rcan1 enhances CREB activation and BDNF expression in the brain}

Because RCAN1 is a modulator of CaN activity (Rothermel et al., 2003; Vega et al., 2003; Hoeffer et al., 2007) and CaN is known to regulate CREB (Bito et al., 1996; Kingsbury et al., 2007), we examined $\mathrm{CaN}$ and CREB activity in Rcan $1 \mathrm{KO}$ mice. Protein lysates from the PFC, amygdala (AM), and nucleus accumbens (NAc), brain regions involved in human and rodent anxiety (Garcia et al., 1999; Liotti et al., 2000; Wall and Messier, 2000; Deacon et al., 2003; Myers-Schulz and Koenigs, 2012), were prepared from Rcan1 KO and WT littermates. In PFC lysates, we detected elevated CaN activity from $R$ can $1 \mathrm{KO}$ mice $\left(t_{(13)}=2.51, p=0.0259\right.$; Fig. $1 A$ ), which is consistent with our previous findings in the hippocampus (Hoeffer et al., 2007). This difference was not due to changes in total $\mathrm{CaN}$ expression (Fig. $1 A$ ). Interestingly, we observed a significant increase in phospho-CREB at S133 (pCREB S133) in the PFC, AM, and NAc lysates from Rcan1 KO mice compared with WT littermates (PFC percentage pCREB of WT levels, $t_{(12)}=4.714, p<0.001$; AM percentage pCREB of $\mathrm{WT}, t_{(11)}=-2.532, p=0.028$; NAc percentage pCREB of WT, $t_{(11)}=4.258, p<0.001$; Fig. $\left.1 B\right)$. This effect was also observed in other brain regions, including the hippocampus and striatum (data not shown). To confirm the specificity of our pCREB S133 antibody, we verified the pCREB signal in brain tissue isolated from CREB knockdown mice using viral-mediated Cre removal of floxed Creb (Mantamadiotis et al., 2002) and reprobed with total CREB antibody (Fig. 1C).

We next asked whether CaN activity contributed to the enhanced CREB phosphorylation in Rcan $1 \mathrm{KO}$ mice by measuring pCREB levels after acute pharmacological inhibition of CaN with FK506. WT and Rcan1 KO mice were injected with FK506 or vehicle $60 \mathrm{~min}$ before isolation of PFC and NAc tissues. We found that FK506 treatment abolished the pCREB difference observed between the two genotypes in the PFC (percentage pCREB of WT-vehicle levels, $\chi_{(3)}^{2}=14.747, p=0.002$; Fig. 1D). Post hoc comparisons indicated a significant difference between WT and KO vehicle conditions $(p<0.001)$, which was eliminated with acute FK506 treatment (WT-FK506 vs KO-FK506, $p=1.000$ ). FK506 increased pCREB levels in WT mice (WT-FK506 vs WT- vehicle, $p=0.014$ ), which is consistent with previous reports (Bito et al., 1996; Liu and Graybiel, 1996), and decreased it in Rcan1 KO mice (KO-FK506 vs WT-vehicle, $p=0.466$ ), effectively eliminating the pCREB difference between the two genotypes. The same effect was observed in the NAc (Fig. 1D; percentage pCREB of WT-vehicle levels, $\chi_{(3)}^{2}=8.669, p=0.034$ WT-vehicle vs KO-vehicle, $p=0.023$; KO-FK506 vs WT-FK506, $p=1.000$; KO-FK506 vs WT-vehicle, $p=0.380$ ). We also observed similar results with pCREB following treatment of PFC slices using a different $\mathrm{CaN}$ inhibitor, CsA (data not shown). Together, these data demonstrate that $\mathrm{CaN}$ activity regulates CREB phosphorylation in both WT and Rcan1 KO mice and its acute blockade normalizes mutant and WT levels of CREB activation to similar levels.

To test the functional relevance of the higher pCREB levels in Rcan1 KO mice, we assessed mRNA and protein levels of a well characterized CREB-responsive gene, Bdnf, in the PFC (Finkbeiner et al., 1997). Consistent with enhanced CREB activity in Rcan1 KO mice, we detected increased levels of $B d n f$ mRNA and pro-BDNF protein $(\sim 32 \mathrm{kDa}$; Fayard et al., 2005; pro-BDNF levels, Mann-Whitney $U_{(12)}=8.308, p=0.004$; Fig. $1 E$ ). Our CREB activation results suggest that, in this context, RCAN1 acts to facilitate $\mathrm{CaN}$ activity. However, $\mathrm{CaN}$ has been reported to negatively regulate CREB activation (Bito et al., 1996; Chang and Berg, 2001) and we have shown that loss of RCAN1 leads to increased CaN activity in the brain (Hoeffer et al., 2007; Fig. 1A). To attempt to reconcile this apparent discrepancy, we examined whether RCAN1 may act to regulate the subcellular localization of phosphatases involved in CREB activity.

\section{RCAN1-CaN interaction regulates phosphatase localization in the brain}

Because we found that Rcan 1 deletion unexpectedly led to CREB activation in the brain (Fig. 1), it may be that, in addition to regulating CaN enzymatic activity, RCAN1 may function in the subcellular localization of CaN. In this scenario, RCAN1 would exert control over CaN substrates via spatial restriction of $\mathrm{CaN}$ activity. To test this idea, we first determined whether we could pharmacologically manipulate RCAN1-CaN interaction in the brain. To do this, we treated hippocampal slices with dipyridamole $(5 \mu \mathrm{M})$, a recently identified small molecule inhibitor of RCAN-CaN interaction (Carme Mulero et al., 2010), or with vehicle for $30 \mathrm{~min}$. Then we extracted proteins from the treated slices, immunoprecipitated $\mathrm{CaN}$, and blotted the immunoprecipitate to probe for RCAN1. We found that dipyridamole reduced the levels of RCAN1 bound to CaN (Fig. 2A). Having confirmed our ability to manipulate RCAN1-CaN binding, we next tested the idea that blocking their interaction would alter CaN localization.

We performed subcellular fractionation of hippocampal slices treated with dipyridamole or vehicle and then probed the fractionates for CaN using Western blotting. Consistent with our idea that RCAN1 regulates CaN localization, we found reduced $\mathrm{CaN}$ levels in nuclear fractions isolated from dipyridamoletreated tissue (percentage CaN of vehicle levels, $t_{(5)}=3.805, p=$ 0.013; Fig. $2 B$ ). Because $\mathrm{CaN}$ also regulates the activity of PP1, another important phosphatase known to regulate CREB activity (Alberts et al., 1994; Genoux et al., 2002), we tested the idea that disrupting RCAN1-CaN interaction would also alter PP1 nuclear localization. Indeed, we found that dipyridamole reduced PP1 levels in the nuclear fraction (percentage PP1 of vehicle levels, $t_{(4)}=3.217, p=0.032$; Fig. $2 B$ ). To determine whether a similar mechanism might be at work in the Rcanl KO brain, we next 
A
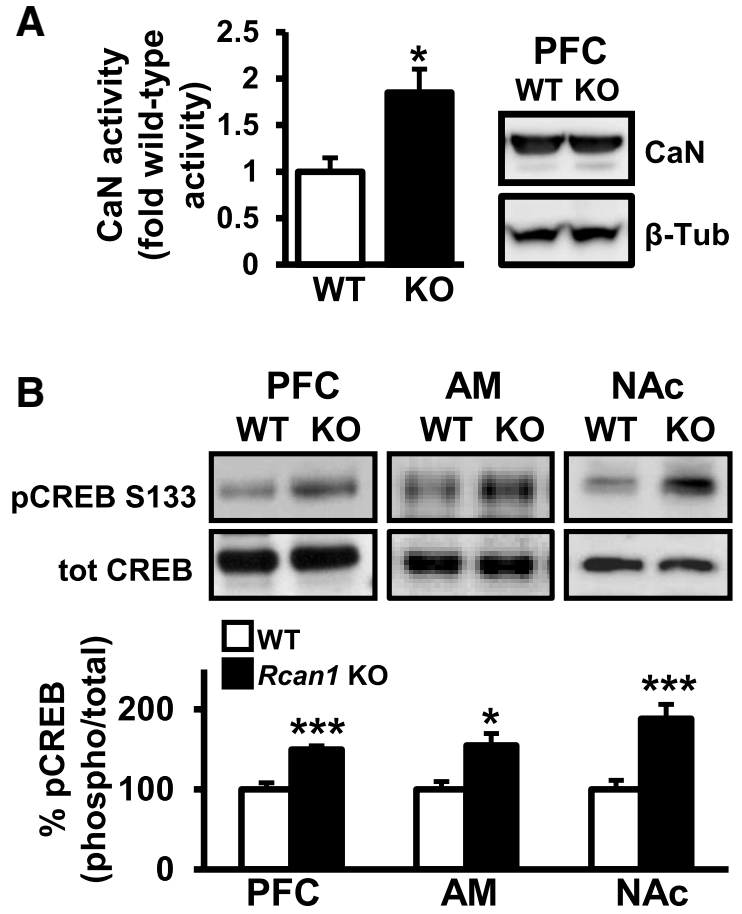

C

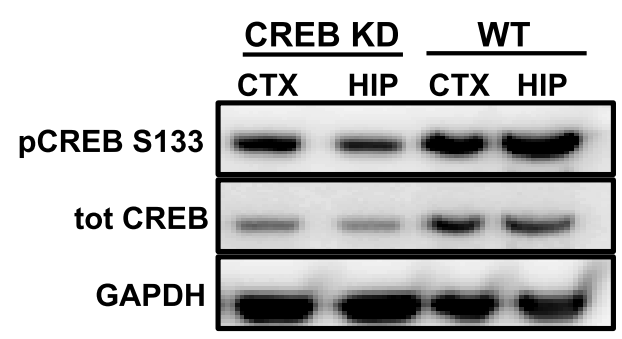

D

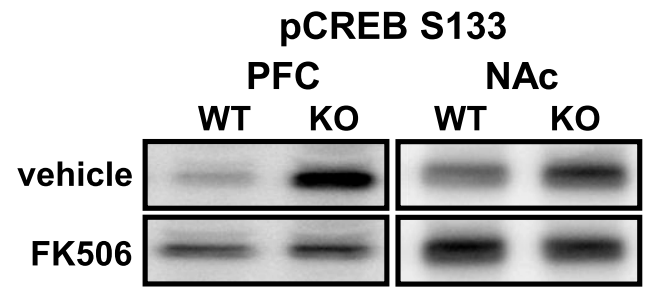

$\square \mathrm{WT}+$ vehicle Rcan1 KO + vehicle

曲 WT + FK506 QRcan1 KO + FK506

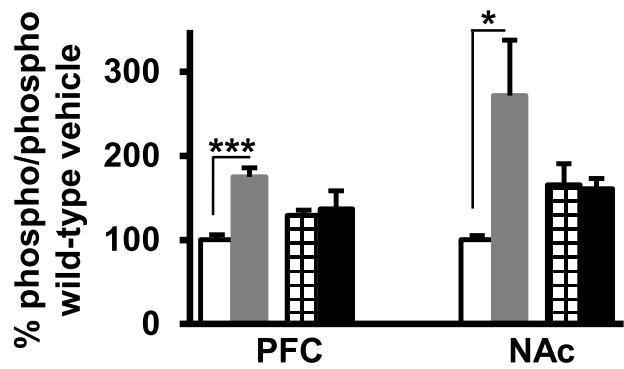

E
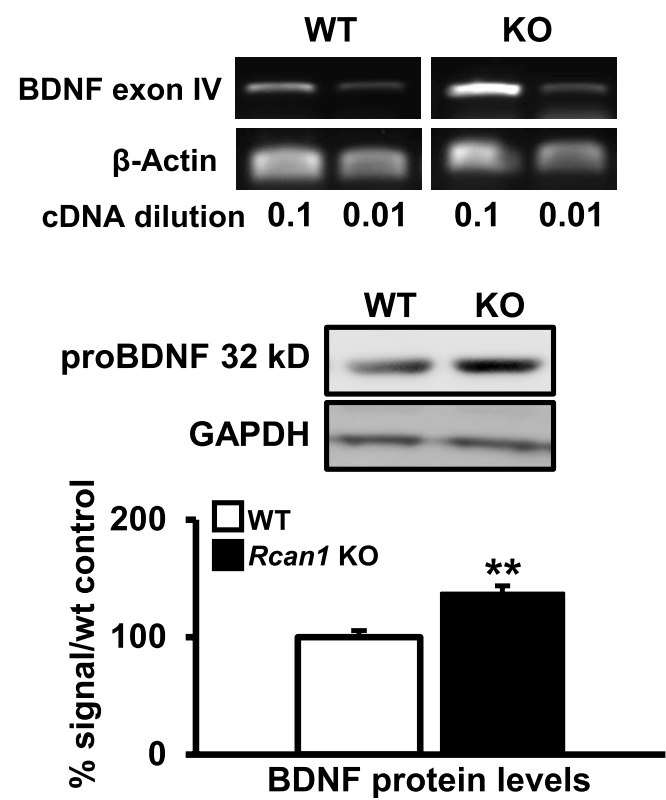

Figure 1. CREB activation and BDNF expression are increased in Rcan $1 \mathrm{KO}$ mice. $A$, CaN activity is elevated in the PFC of Rcan $1 \mathrm{KO}$ mice $(p=0.0259)$ and is not due to different protein levels of CaN (60 kDa). $\beta$-Tubulin ( $\beta$-Tub), loading control. $N=9 \mathrm{KO}, 6$ WT. B, Enhanced pCREB S133 is seen in the PFC, AM, and NAc of $R$ can $1 \mathrm{~K} 0$ mice. Total CREB levels are unchanged between genotypes. C, Identity confirmation of the pCREB signal used for quantification in this study. Viral-mediated CREB knockdown (KD) tissue from the cortex (ctx) and hippocampus (hip) were probed for pCREB S133 and reprobed for total (tot) CREB on the same blot. GAPDH, loading control. $D$, Acute blockade of CaN activity with FK506 eliminates the CREB activation differences between Rcan $1 \mathrm{~K} 0$ and WT mice. Pairwise comparisons of PFC percentage pCREB of WT-vehicle levels revealed a significant difference between WT and K0 vehicle groups $(p<0.001)$ and no difference between K0-FK506 and WT-vehicle groups $(p=0.446)$ or between WT-FK506 and KO-FK506 groups $(p=1.000)$. N = 4 mice/group. The same effect was observed in the NAc. $\boldsymbol{E}$, Bdnf mRNA (exon IV) and pro-BDNF protein levels ( $32 \mathrm{kDa}$ ) are increased in the PFC of Rcan1 KO mice. Semiquantitative PCR of cDNA synthesized from Bdnf mRNA bearing exon IV (confirmed with intron-spanning primers). $N=4$ mice/genotype. Western blot of pro-BDNF levels. $N=4-6$ mice/genotype. $\beta$-Actin mRNA levels and GAPDH staining confirms equal loading in each lane. ${ }^{*} p<0.05,{ }^{* *} p<0.01,{ }^{* * *} p<0.001$.

fractionated proteins from hippocampal slices of Rcan1 KO mice. Similar to dipyridamole treatment, we found that Rcan 1 deletion reduces $\mathrm{CaN}$ and $\mathrm{PP} 1$ levels in the nuclear fraction (percentage CaN of WT levels, $t_{(4)}=3.016, p=0.039$; percentage PP1 of WT levels, $t_{(3)}=4.826, p=0.017$; Fig. $2 B$ ). To determine whether RCAN1 overexpression would exert the opposite effect on CaN and PP1 localization, we fractionated hippocampal tissue isolated from RCAN1-overexpressing mice $\left(\right.$ CamkII $\left.\alpha-R C A N 1^{T g 1 a}\right)$. Con- sistent with a role for RCAN1 in promoting CaN and PP1 trafficking to the nucleus, we found increased CaN and PP1 levels in nuclear fractions of RCAN1-overexpressing hippocampi (percentage $\mathrm{CaN}$ of control WT levels, $t_{(5)}=-4.252, p=0.008$; percentage PP1 of control WT levels, $t_{(4)}=-3.049, p=0.038$; Fig. $2 B$ ) while reducing them in the cytoplasmic fraction (data not shown). These results support the idea that CREB phosphorylation may be enhanced in Rcan 1 KO brains because the removal 
of RCAN1 reduces phosphatase localization in the nuclear compartment.

Finally, to test this idea, we examined CREB phosphorylation following acute disruption of RCAN1-CaN interaction in dipyridamole-treated hippocampal slices. Similar to what we observed in Rcan1 KO brains (Fig. 1), we found that dipyridamole induced CREB activation (Fig. 2C). These combined data support the idea that RCAN1 functions as an important regulator of CREB activity via the control of subcellular phosphatase trafficking. Interestingly, we did not find reduced pCREB S133 in lysates from CamkII $\alpha$ RCAN1 $1^{T g 1 a}$ slices (data not shown), indicating that in addition to RCAN1/CaN signaling, other cellular signaling pathways likely function to upregulate CREB activity in these mice. Given the important role of CREB, BDNF, and $\mathrm{CaN}$ in the manifestation of anxiety and depression (for review, see Carlezon et al., 2005; Wu et al., 2008; Frielingsdorf et al., 2010; Rakofsky et al., 2012), we next explored the effects of RCAN1 levels on affective behaviors.

RCAN1 levels regulate the expression of innate anxiety

To examine whether RCAN1 is involved in anxiety-related behaviors via $\mathrm{CaN}$, we first tested Rcan $1 \mathrm{KO}$ mice in the OFA assay. We observed a significant increase in their time spent in the center of a $27.3 \times$ $27.3 \mathrm{~cm}^{2}$ arena compared with WT littermates $\left(t_{(31)}=-2.736, p=0.010\right)$, which suggests reduced anxiety in Rcan $1 \mathrm{KO}$ mice (Fig. 3A). This observation was mirrored by the significantly greater distance that Rcan1 KO mice moved in the center of the arena $\left(t_{(33)}=3.757, p<0.001\right)$ but not by differences in total distance traveled $\left(t_{(33)}=1.511, p=0.140\right.$; Fig. $\left.3 B\right)$. Thus, the differences in center time and center distance were not the result of an increased locomotor response in $\mathrm{KO}$ mice, but were consistent with reduced anxiety. Similar results were found testing another cohort in a larger arena $(40 \times 40$ $\mathrm{cm}^{2} ; t_{(15)}=-2.619, p=0.019$; Fig. $3 C$ ), indicating that the size of the testing area did not confound our OFA observations. A more detailed examination of distance traveled over time showed that Rcan1 KO mice exhibited higher levels of exploratory behavior early in the test, which is consistent with an initial reduced anxiogenic response to the novel environment (Fig. 3D; $1-3 \mathrm{~min}$ bin, $t_{(20)}=7.959, p=0.046 ; 4-6 \mathrm{~min}$, $t_{(20)}=1.498, p=0.156$; 7-9 $\mathrm{min}, t_{(20)}=$ $0.506, p>0.6 ; 10-12 \mathrm{~min}, t_{(20}=-0.390$, $p>0.7 ; 13-15$ min, $t_{(20)}=-0.369, p>$
A

IP: CaN

IP: CaN
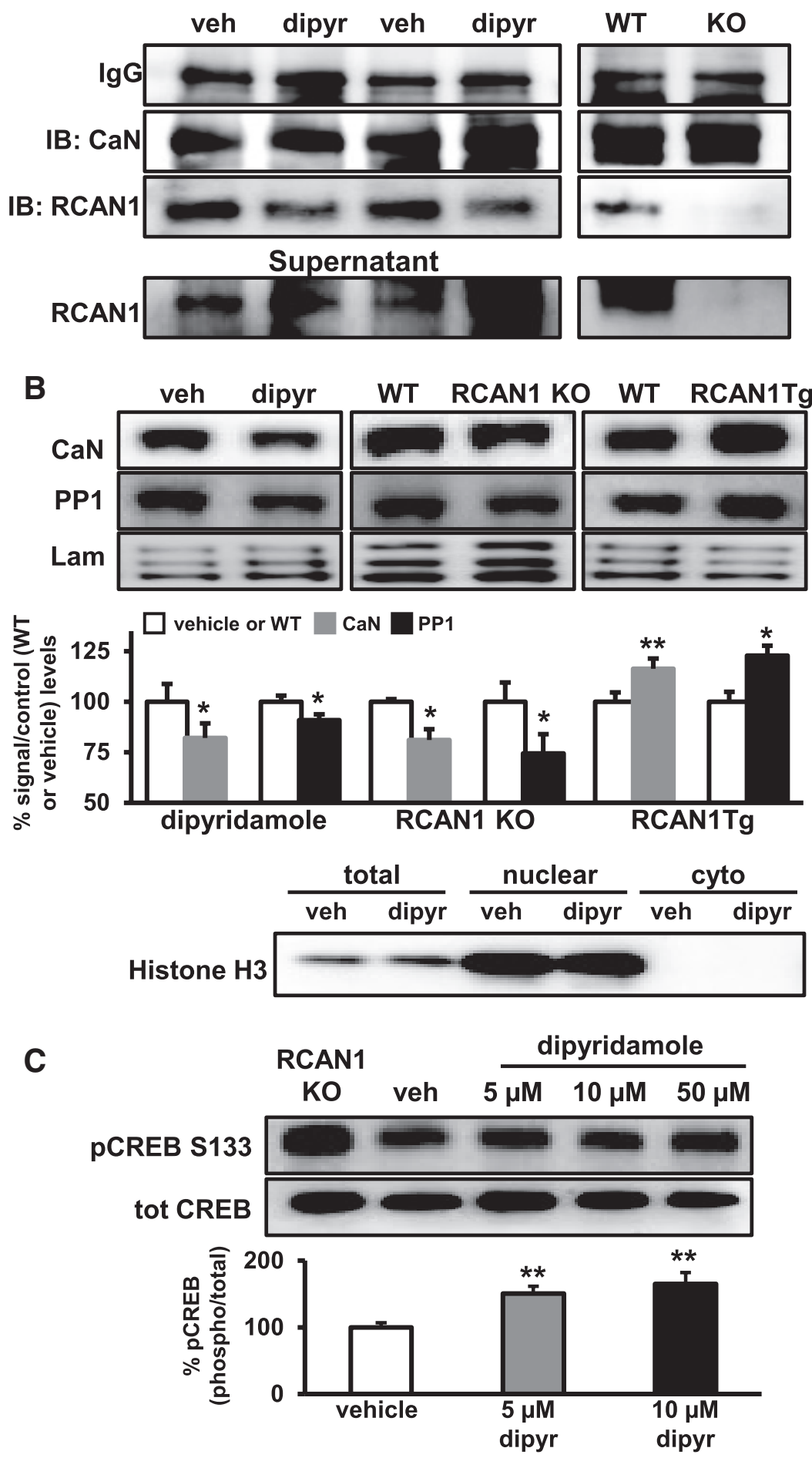

Figure 2. Disruption of RCAN1-CaN interaction alters subcellular phosphatase localization and leads to CREB activation. $A$, Treatment with $5 \mu$ m dipyridamole (dipyr) disrupts RCAN1 binding to CaN in the hippocampus. Immunoprecipitation of CaN shows reduced RCAN1 interaction with CaN following dipyridamole compared with vehicle treatment (veh). Signal specificity was confirmed using $R$ can $1 \mathrm{KO}$ tissue. $\boldsymbol{B}$, Dipyridamole treatment results in lower nuclear levels of CaN and its substrate, PP1. Genetic removal of RCAN1 (KO) also lowers nuclear levels of CaN and PP1. Conversely, overexpression of RCAN1 (Tg) increases nuclear CaN and PP1 levels. Equal loading and compartment fidelity confirmed with lamin A/C (Lam). Efficacy of subcellular localization protocol confirmed with histone $\mathrm{H} 3$ staining in total protein, nuclear, and cytoplasmic (cyto) fractions. Blots are representative of 2-3 replicates from three independent samples per treatment or genotype. $C$, Disruption of RCAN1-CaN with acute dipyridamole treatment activates CREB in the hippocampus, as measured by pCREB S133. Rcan1 K0 tissue included for comparison. $N=5$ vehicle, $5 \mathrm{WT}+\operatorname{dipyr}(5 \mu \mathrm{M}), 4 \mathrm{WT}+\operatorname{dipyr}(10 \mu \mathrm{M}) .{ }^{*} p<0.05$, ${ }^{* *} p<0.01$. 


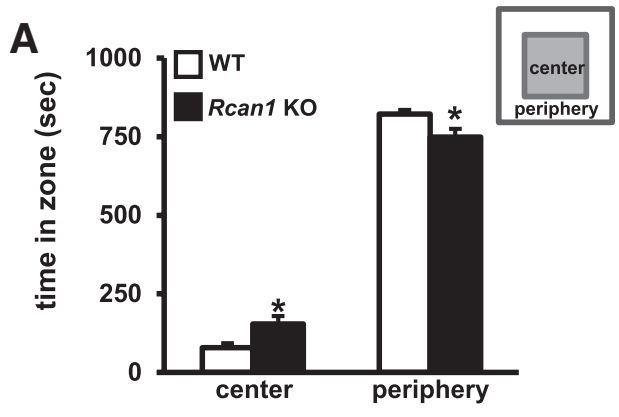

B
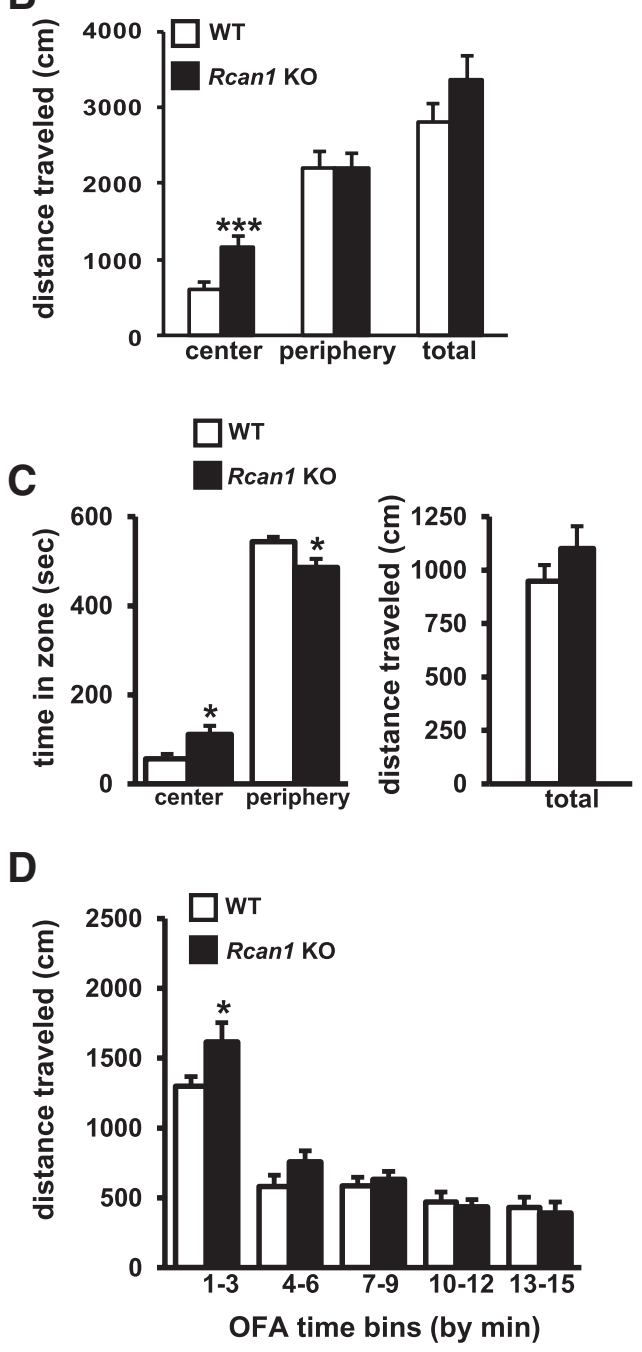

Figure 3. Rcan $1 \mathrm{~K} 0$ mice show decreased measures of anxiety in the OFA assay. $\boldsymbol{A}, R$ Ran $1 \mathrm{KO}$ mice spend more time in the center zone than the periphery of the OFA. $\boldsymbol{B}$, Rcan $1 \mathrm{~K} 0$ mice travel a greater distance in the center zone without significant differences in total movement compared with WT littermates. C, Rcan $1 \mathrm{KO}$ mice also display greater center time when tested in a larger OFA $\left(40 \times 40 \mathrm{~cm}^{2}\right)$. D, The increase in distance traveled by $R$ can $1 \mathrm{~K} 0$ mice in the center zone occurs early during the test. Different cohorts used for data presented in $A-D \cdot A, B, N=14$ $\mathrm{KO}, 21 \mathrm{WT}$, time data for two WT samples lost during data collection. $C, N=8 \mathrm{KO}, 9$ WT. $D, N=$ 11 K0, 11 WT. ${ }^{*} p<0.05,{ }^{* * *} p<0.001$.

0.7). We observed no differences between genotypes in the total time spent moving, at rest, standing up vertically, or in stereotypical movements (data not shown).

We next examined the behavior of Rcan $1 \mathrm{KO}$ mice in the EPM. Compared with their WT littermates, Rcan1 KO mice spent significantly greater time in the open arms of the EPM (open- arm, Mann-Whitney $U_{(22)}=4.0, p<0.001$; closed arm, MannWhitney $\left.U_{(22)}=81.0, p=0.166\right)$ and less time in the center zone (Mann-Whitney $U_{(22)}=104.0, p=0.004$; Fig. $4 A$ ). As with our OFA data, Rcan $1 \mathrm{KO}$ mice showed increased open-arm time early in the EPM test compared with WT mice (first minute open-arm time WT vs KO, Mann-Whitney $U_{(20)}=4.460, p<0.001$; Fig. $4 B)$. WT mice displayed low open-arm times in the first minute, which increased significantly by the third minute of testing (first vs third minute, $t_{(10)}=-3.620, p=0.007$; Fig. $4 B$ ). Consistent with the OFA data, these results suggest reduced anxiety in Rcan 1 $\mathrm{KO}$ mice. These effects were not due to alterations in spontaneous arm entries because there was no difference between genotypes in their frequency of arm entries $\left(t_{(22)}=-0.267, p>0.7\right)$. The effects also were not due to locomotor differences because the genotypes were indistinguishable in total distance traveled or velocity of ambulation (total distance, $t_{(20)}=-0.035, p>0.9$; velocity, $t_{(20)}=-0.034, p>0.9$; Fig. $4 C$ ). Therefore, combined with the OFA results, the EPM behavior of Rcan1 KO mice support a role for RCAN1 in the display of innate anxiety.

Patients suffering from panic disorders and obsessive-compulsive disorder manifest impaired PPI, a measure of sensorimotor gating (Ludewig et al., 2002). Given the reduced anxiety in Rcan1 KO mice, we tested these mice for abnormal PPI. We found no difference in PPI between Rcanl KO mice and WT littermates across a range of acoustic prepulse intensities (Fig. 4D; percentage inhibition of startle response: $74 \mathrm{~dB}, t_{(26)}=-0.123$, $p>0.9 ; 78 \mathrm{~dB}, t_{(26)}=0.601, p>0.5 ; 82 \mathrm{~dB}, t_{(26)}=1.232, p>0.2$; $86 \mathrm{~dB}, t_{(26)}=1.222, p>0.2 ; 90 \mathrm{~dB}, t_{(26)}=1.753, p>0.091$; startle test: $t_{(26)}=-0.113, p>0.9$; null period: $\left.t_{(26)}=-0.109, p>0.9\right)$. This demonstrates that the anxiety phenotype in Rcan1 KO mice is not the result of abnormal sensorimotor gating.

Since RCAN1 removal reduced the display of anxiety in Rcan 1 KO mice, we next tested whether RCAN1 overexpression could increase anxiety behaviors. We took advantage of two conditional flox-ON RCAN1 transgenic mouse lines (Tg1 and Tgla) that overexpress human RCAN1 protein at high or low levels, respectively, in the presence of Cre recombinase (Oh et al., 2005). We used two Cre-driver lines to activate RCAN1 overexpression at different developmental time points, Nse-Cre during development (onset at about embryonic day 16.5; Forss-Petter et al., 1990 ) and T29-CamkII $\alpha$-Cre postdevelopmentally (onset at about postnatal day 14; Hoeffer et al., 2008). Overexpression of RCAN1 was confirmed by Western blots using antibodies against RCAN1 (Vega et al., 2003; Hoeffer et al., 2007) and the FLAG epitope tagged to the RCAN1 transgenic construct (Oh et al., 2005; Fig. 4E). RCAN1 overexpression using either Cre driver had no detectable effect in the OFA assay (Table 1). In the EPM assay, however, RCAN1 overexpression early in development under Nse-Cre in RCAN1 ${ }^{\text {Tgla }}$ mice was shown to decrease open-arm time compared with control WT (no Cre) littermates (MannWhitney $U_{(83)}=2.010, p=0.044$; Fig. $4 F$ ). This effect was not due to group differences in locomotor activity (distance moved $t_{(18)}=1.683, p=0.110$ ) or sensorimotor gating (Table 2 ), which supports the idea that the decreased open-arm time in Nse$R C A N 1^{T g l a}$ mice represents greater anxiety. However, overexpression of the other RCAN1 construct $\left(R C A N 1^{T g l}\right)$ under the same Nse-Cre driver did not affect EPM open-arm time, (MannWhitney $U_{(18)}=0.140, p>0.9$; Fig. $4 F$ ). Also, postdevelopmental RCAN1 overexpression under CamkII $\alpha$-Cre did not affect EPM open-arm time (CamkII $\alpha-R C A N 1^{\text {Tgla }}$ open-arm time, Mann-Whitney $U_{(70)}=0.018, p>0.9$; CamkII $\alpha$ $R C A N 1^{T g 1}$ open-arm time, Mann-Whitney $U_{(28)}=-0.873$, $p>0.4$; Fig. $4 F$ ). Combined with the behavioral results in 
A

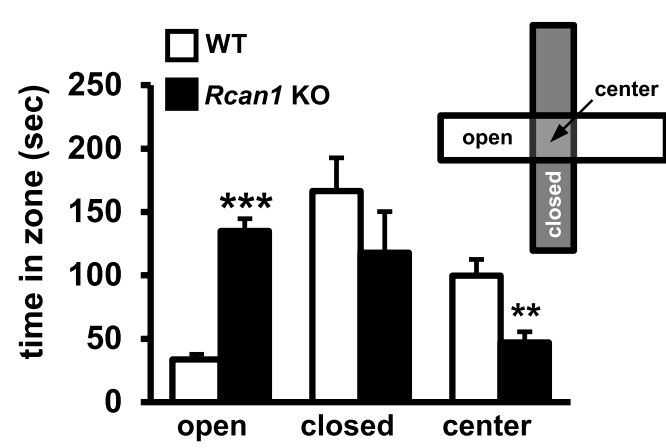

B

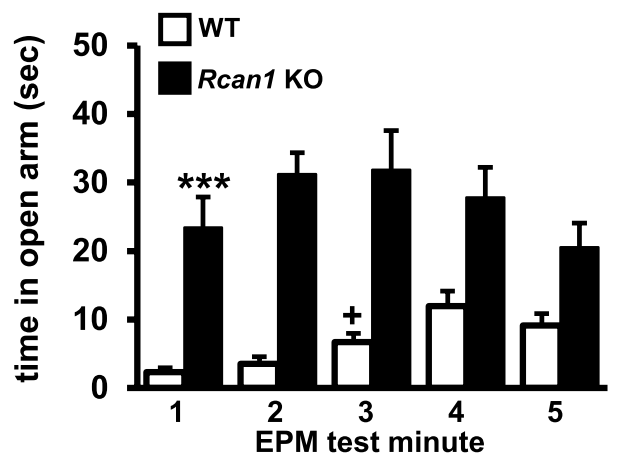

C

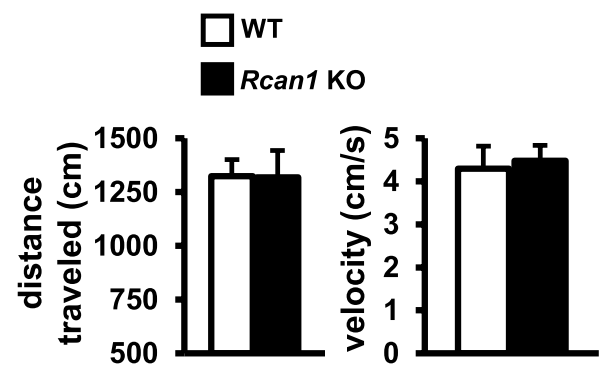

D

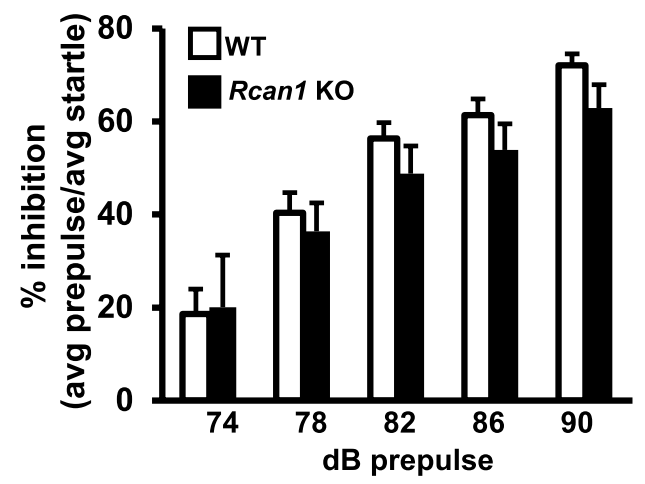

$\mathbf{E}$

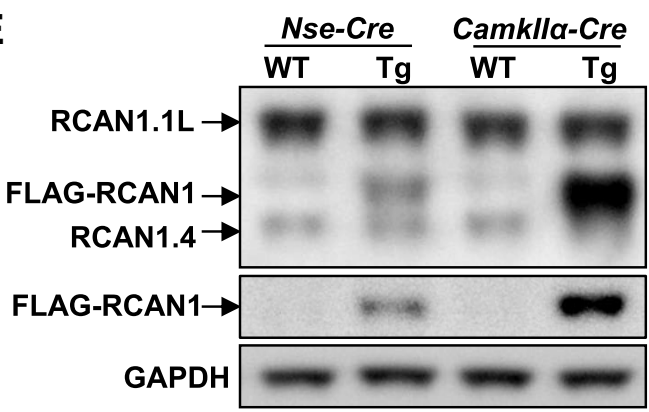

$\mathbf{F}$
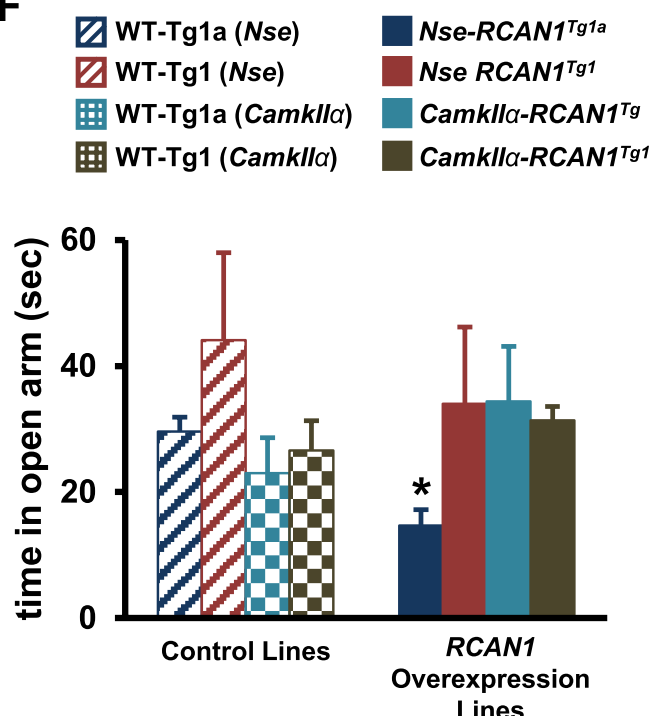

Figure 4. Rcan $1 \mathrm{KO}$ mice show decreased measures of anxiety in the EPM. $A, R$ Ran $1 \mathrm{KO}$ mice spend significantly more time exploring the open arms of the EPM compared with their WT littermates. $N=10 \mathrm{KO}, 12$ WT. $B$, Rcan $1 \mathrm{KO}$ mice enter the open arms early in the EPM test (minute 1) whereas their WT littermates increased open-arm exploration starting at the third minute of testing compared with minute $1 . N=10 \mathrm{KO}, 9$ WT. C, Total distance moved and speed of $R$ can $1 \mathrm{KO}$ mice are indistinguishable from WT mice in the EPM. N=10 K0, 12 WT. D, Rcan $1 \mathrm{KO}$ mice display similar PPI of acoustic startle responses compared with their WT littermates. $\boldsymbol{E}$, Western blot analysis of RCAN1 expression in the PFC of RCAN1 transgenic (Tg) mice used for this study. Upper blot is stained with an RCAN1 antibody that recognizes endogenously expressed RCAN1.1L ( $\sim 38 \mathrm{kDa})$ and RCAN1.4 ( $\sim 28 \mathrm{kDa})$ protein isoforms and transgenically expressed FLAG-tagged human RCAN1.1S protein ( $30 \mathrm{kDa}$; for more details, see $0 \mathrm{~h}$ et al., 2005; Hoeffer et al., 2007). Lower blot is stained with a FLAG antibody, confirming expression of transgene. Nse-Cre driver line, Camkll $\alpha$-Cre (T-29) driver line. GAPDH, loading control. Image is representative of three independent blots. WT represents the WT control for each breeding cross. $\boldsymbol{F}$, Mice overexpressing human RCAN1 early in development (Nse-RCAN $1^{\text {Tg1a }}$ ) display decreased EPM open-arm time compared with WT littermates. No difference in open-arm time was observed driving an alternative RCAN1 construct $\left(R C A N 1^{T g} 1\right.$ ) with the same Nse-Cre driver. No difference in open-arm time was also observed with postdevelopmental RCAN1 overexpression (Camkll $\alpha$-Cre) of either RCAN1 construct. WT-Tg1a (Nse) denotes control RCAN1 ${ }^{T g 1 a}$-only (no Cre) "WT" littermates from RCAN1 ${ }^{T g 1 a} \times$ Nse-Cre lines. WT-Tg1 (Nse) denotes control RCAN1 ${ }^{T g 1}$-only (no Cre) "WT" littermates from RCAN1 $1^{T g 1} \times N$ se-Cre lines.

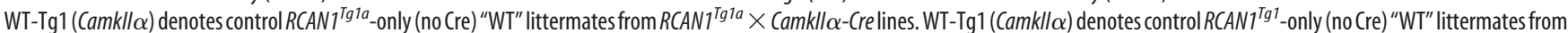

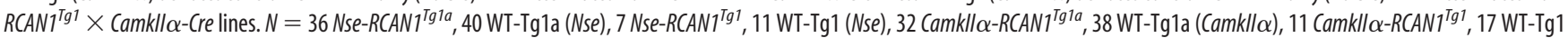
(Camkll $\alpha$ ). For some datasets not normally distributed, Mann-Whitney analysis was used. ${ }^{*} p<0.05,{ }^{* *}$ or $+p<0.01,{ }^{* * *} p<0.001$. 
Table 1. OFA activity of mice that overexpress human RCAN1 ${ }^{a}$

\begin{tabular}{|c|c|c|c|c|c|c|c|c|c|c|c|c|c|c|c|c|c|}
\hline \multirow[b]{2}{*}{ Genotype } & \multicolumn{2}{|c|}{ Time/zone (s) } & \multicolumn{3}{|c|}{ Distance/zone (cm) } & \multicolumn{3}{|c|}{ Ambulatory (s) } & \multicolumn{3}{|l|}{ Resting (s) } & \multicolumn{3}{|l|}{ Vertical (s) } & \multicolumn{3}{|c|}{ Stereotypic (s) } \\
\hline & Periphery & Center & Periphery & Center & Total & Periphery & Center & Total & Periphery & Center & Total & Periphery & Center & Total & Periphery & Center & Total \\
\hline \multicolumn{18}{|c|}{ Nse-RCAN1Tg1a } \\
\hline Mean & 767.6 & 132.4 & 1576.2 & 513.9 & 2090.1 & 62.1 & 20.8 & 82.9 & 580.1 & 69.9 & 650 & 92 & 7.6 & 99.6 & 125.3 & 25.3 & 150.6 \\
\hline \multicolumn{18}{|c|}{ WT-Tg1a (Nse) } \\
\hline Mean & 779.5 & 120.5 & 1596.3 & 510.6 & 2106.9 & 61.7 & 20.8 & 82.5 & 594.9 & 63 & 658 & 98.4 & 6.3 & 104.7 & 122.8 & 22.4 & 145.2 \\
\hline SEM & 10.8 & 10.8 & 99.7 & 60.6 & 128.4 & 4.9 & 2.8 & 6.2 & 12.3 & 6.8 & 9.5 & 8.3 & 1.2 & 9.1 & 3.2 & 2.1 & 3.9 \\
\hline \multicolumn{18}{|c|}{ Nse-RCAN1 $1^{\operatorname{Tg} 1}$} \\
\hline Mean & 718.5 & 181.5 & 1633.3 & 572.3 & 2205.6 & 69.8 & 19.4 & 89.2 & 549.5 & 101.7 & 651.2 & 63.7 & 5.5 & 69.2 & 114.4 & 29.8 & 144.2 \\
\hline SEM & 35.8 & 35.8 & 92.1 & 78.2 & 140.9 & 9.9 & 3.1 & 11.1 & 29.2 & 27.2 & 16.1 & 9.2 & 2.5 & 10.3 & 4.8 & 5.3 & 6.6 \\
\hline \multicolumn{18}{|c|}{ WT-Tg1 (Nse) } \\
\hline Mean & 732.1 & 167.9 & 1551.9 & 623.0 & 2174.9 & 63.0 & 28.2 & 91.3 & 536.0 & 106.5 & 642.5 & 44.8 & 3.72 & 48.5 & 115.4 & 35.8 & 151.2 \\
\hline SEM & 37.2 & 37.2 & 74.7 & 88.6 & 105.3 & 9.2 & 5.4 & 10.7 & 27.1 & 29.5 & 14.0 & 8.1 & 0.7 & 8.6 & 7.0 & 7.1 & 3.0 \\
\hline$p$ value & 0.804 & 0.804 & 0.502 & 0.679 & 0.864 & 0.622 & 0.184 & 0.894 & 0.737 & 0.905 & 0.686 & 0.139 & 0.495 & 0.131 & 0.904 & 0.517 & 0.333 \\
\hline Mean & 746.2 & 153.8 & 1873.5 & 706.8 & 2580.3 & 75.1 & 30 & 105 & 546.7 & 72.7 & 619.4 & 76.4 & 7 & 83.4 & 128.7 & 29.7 & 158.3 \\
\hline SEM & 17.9 & 17.9 & 89.5 & 61.7 & 120.3 & 4.7 & 2.8 & 6.2 & 12.6 & 8.2 & 9 & 7.2 & 1.4 & 8.1 & 2.6 & 2.7 & 3.3 \\
\hline$p$ value & 0.74 & 0.74 & 0.59 & 0.765 & 0.57 & 0.77 & 0.535 & 0.604 & 0.659 & 0.512 & 0.844 & 0.92 & 0.496 & 0.804 & 0.504 & 0.679 & 0.274 \\
\hline \multicolumn{18}{|c|}{ Camk $\| \alpha-R C A N 1^{T g 1}$} \\
\hline Mean & 799.5 & 100.5 & 1736.5 & 357.4 & 2093.9 & 70 & 13.3 & 83.3 & 595 & 50.7 & 645.7 & 50.7 & 1.3 & 52 & 134.4 & 18.7 & 153.1 \\
\hline SEM & 13.2 & 13.2 & 123.6 & 43.1 & 137.6 & 6.6 & 1.8 & 7 & 14.8 & 7.7 & 11 & 7.2 & 0.6 & 7.3 & 3.4 & 2.4 & 4.2 \\
\hline \multicolumn{18}{|c|}{ WT-Tg1 (Camkll $\alpha)$} \\
\hline Mean & 822.1 & 77.9 & 1710.1 & 286.1 & 1996.3 & 69.4 & 10.7 & 80.1 & 619.4 & 37.3 & 656.7 & 49.9 & 1.1 & 51 & 133.3 & 15 & 148.3 \\
\hline SEM & 10.5 & 10.5 & 79.4 & 45.2 & 114.1 & 4 & 1.9 & 5.3 & 14.2 & 5.4 & 10.6 & 7 & 0.7 & 7.2 & 3.5 & 1.9 & 4.6 \\
\hline$p$ value & 0.191 & 0.191 & 0.859 & 0.264 & 0.59 & 0.938 & 0.331 & 0.719 & 0.247 & 0.168 & 0.481 & 0.935 & 0.835 & 0.922 & 0.826 & 0.238 & 0.453 \\
\hline
\end{tabular}

${ }^{a}$ Transgenic mice that overexpress human RCAN1 under the control of either a developmental (Nse) or postdevelopmental (CamkIl $\alpha$ ) Cre driver show no difference in OFA activity. Two different transgenic RCAN1 lines were used (Oh et al., 2005). No combination of Cre driver and transgenic RCAN1 lines showed any effect on OFA measures used when compared to controls. $p$ value obtained from two-sided independent $t$ test. $p$ Values compare Tg vs WT for each line.

Rcan1 KO mice, these EPM results suggest that removal of RCAN1 reduces the expression of spontaneously evoked anxiety and that RCAN1 overexpression, when the onset is during early development, may increase it. These data are consistent with the idea that RCAN1 affects the manifestation of innate anxiety.

\section{Pharmacological inhibition of $\mathrm{CaN}$ rescues the reduced anxiety exhibited by Rcan $1 \mathrm{KO}$ mice}

Because RCAN1 is a potent regulator of CaN activity (Vega et al., 2003) and Rcan1 KO mice display increased CaN activity in the hippocampus (Hoeffer et al., 2007) and PFC (Fig. 1A), we tested whether acute pharmacological inhibition of $\mathrm{CaN}$ could restore anxiety to normal levels in Rcan $1 \mathrm{KO}$ mice. WT and Rcan1 KO mice were injected intraperitoneally with either vehicle or the CaN inhibitor FK506 before testing in the OFA assay. Consistent with our data in RCAN1-overexpressing transgenic mice (Fig. $4 F$ ), we found that FK506 treatment decreased the time that both genotypes spent in the center zone (Fig. $5 \mathrm{~A}$; main effect of genotype, $F_{(1,46)}=8.095, p=0.007$; main effect of FK506, $F_{(1,46)}=$ 15.273, $p<0.001$; FK506 $\times$ genotype, $\left.F_{(1,46)}=0.360, p>0.5\right)$. This suggests that inhibiting CaN activity increases the display of anxiety. Importantly, post hoc comparisons revealed that FK506 treatment decreased the time spent in the center zone by Rcan 1 $\mathrm{KO}$ mice to the same amount as vehicle-treated WT mice ( $p=$ $0.851)$. Analyzing distance traveled in the OFA, we found that FK506 treatment significantly reduced total locomotor activity in both genotypes, thus preventing direct comparisons using absolute measurements of distance (Fig. 5B; main effect of FK506, $F_{(1,46)}=120.248, p<0.001$; main effect of genotype, $F_{(1,46)}=$ $0.001, p>0.9$; genotype $\times$ FK506, $\left.F_{(1,46)}=0.367, p>0.5\right)$. To control for the FK506-induced reduction in movement, we com- pared the ratios of distance traveled in each OFA zone to total distance traveled during the test period for each group (Fig. 5C). Using this measure, we found that FK506 treatment decreased the relative distance that both genotypes traveled in the center zone (main effect of FK506, $F_{(1,46)}=32.463, p<0.001$; main effect of genotype, $F_{(1,46)}=12.873, p<0.001 ;$ FK506 $\times$ genotype, $\left.F_{(1,46)}=0.317, p>0.5\right)$. Consistent with the decrease in center time (Fig. $5 A$ ), this result provides another indicator that inhibiting CaN activity increases anxiety. More specifically, a post hoc comparison showed that the center ratio for FK506-treated Rcan1 KO mice was indistinguishable from that for vehicletreated WT mice ( $p=0.692$; Fig. $5 C$ ), indicating that FK506 blockade of $\mathrm{CaN}$ was able to rescue the reduced anxiety in $\mathrm{KO}$ mice. These data suggest an inhibitory role of RCAN1 on CaN in the expression of anxiety-related behaviors.

To support the OFA results, we also tested the effects of acute CaN blockade on anxiety measured with the EPM assay. To confirm that the pharmacological rescue we observed in the OFA was specific to CaN blockade, we selected another $\mathrm{CaN}$ inhibitor, CsA, for these experiments. Because of the locomotor effects we observed with intraperitoneal administration of FK506 (Fig. 5B), we decided to directly apply CsA to the mouse brain. CsA does not readily cross the blood-brain barrier (Serkova et al., 2000, 2001), which reduces potential confounds arising from systemic CaN blockade. To enable direct application of CsA to the brain, we surgically implanted cannulae in the lateral ventricles (intracerebroventricularly) of Rcan1 KO and WT littermate control mice. Following recovery from surgery, mice were infused with CsA via the cannulae and then tested in the EPM after a $60 \mathrm{~min}$ incubation period. In agreement with our earlier results, we found that vehicle-treated Rcan1 KO mice showed increased open-arm time compared with vehicle-treated WT mice, indicat- 
Table 2. EPM activity and PPI in transgenic mice overexpressing human RCAN1 ${ }^{a}$

\begin{tabular}{|c|c|c|c|c|c|c|c|c|c|c|c|c|}
\hline \multirow[b]{3}{*}{ Genotype } & \multicolumn{5}{|l|}{ EPM } & \multicolumn{7}{|l|}{ PPI } \\
\hline & \multicolumn{3}{|c|}{ Time in zone (s) } & \multirow{2}{*}{$\begin{array}{l}\text { Dist } \\
(\mathrm{cm})\end{array}$} & \multirow{2}{*}{$\begin{array}{l}\text { Vel } \\
(\mathrm{cm} / \mathrm{s})\end{array}$} & \multirow{2}{*}{$\begin{array}{l}\mathrm{dB} \\
120\end{array}$} & \multicolumn{6}{|c|}{ Percentage inhibition (pre-dB) } \\
\hline & Closed & Open & Center & & & & Null & 74 & 78 & 82 & 86 & 90 \\
\hline \multicolumn{13}{|c|}{ Nse-RCAN1 ${ }^{\text {Tg1a }}$} \\
\hline Mean & 242.7 & 16.2 & 38.6 & 1121.3 & 3.8 & 590.5 & 48.2 & 20.4 & 44.2 & 52.8 & 64.1 & 71.8 \\
\hline SEM & 4.2 & 2.4 & 2.2 & 49.2 & 0.2 & 92.3 & 4.1 & 14 & 11.1 & 11.3 & 10 & 8.2 \\
\hline \multicolumn{13}{|c|}{ WT-Tg1a (Nse) } \\
\hline$p$ value & 0.003 & 0.044 & 0.093 & 0.110 & 0.154 & 0.509 & 0.208 & 0.693 & 0.695 & 0.516 & 0.419 & 0.454 \\
\hline \multicolumn{13}{|c|}{ Nse-RCAN1 ${ }^{T g}$} \\
\hline Mean & 212.9 & 34.0 & 53.1 & 993.6 & 3.2 & & & & & & & \\
\hline SEM & 18.6 & 12.2 & 15.3 & 95.3 & 0.3 & & & & & & & \\
\hline \multicolumn{13}{|c|}{ WT-Tg1 (Nse) } \\
\hline Mean & 189.9 & 44.1 & 44.6 & 1116.6 & 3.8 & & & & & & & \\
\hline SEM & 8.9 & 6.8 & 4.4 & 67.5 & 0.2 & 93.3 & 4.4 & 9.1 & 7.6 & 5.4 & 6.1 & 5.5 \\
\hline \multicolumn{13}{|c|}{ WT-Tg1a (Camkll $\alpha)$} \\
\hline Mean & 229.3 & 26.6 & 43.4 & 1241.9 & 4.2 & 706.8 & 50.6 & 27.9 & 41.5 & 55.8 & 70.7 & 80 \\
\hline SEM & 5.8 & 4 & 4.7 & 60.8 & 0.2 & 91.4 & 10.1 & 17.7 & 9.9 & 5.5 & 6.3 & 5.1 \\
\hline$p$ value & 0.747 & 0.986 & 0.618 & 0.906 & 0.899 & 0.428 & 0.824 & 0.797 & 0.943 & 0.84 & 0.951 & 0.577 \\
\hline \multicolumn{13}{|c|}{ 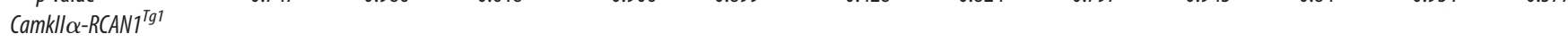 } \\
\hline Mean & 193.8 & 34.4 & 71.5 & 1344.6 & 4.5 & & & & & & & \\
\hline SEM & 10.3 & 8.7 & 8.2 & 57.7 & 0.2 & & & & & & & \\
\hline \multicolumn{13}{|c|}{ WT-Tg1 (Camkll $\alpha)$} \\
\hline Mean & 227.4 & 23 & 49.3 & 1350.2 & 4.6 & & & & & & & \\
\hline SEM & 9.4 & 5.6 & 7.3 & 74.8 & 0.3 & & & & & & & \\
\hline$p$ value & 0.039 & 0.401 & 0.069 & 0.954 & 0.96 & & & & & & & \\
\hline
\end{tabular}

${ }^{a}$ Left columns show EPM performance. Nse-RCAN1 ${ }^{\text {Tg } 1 a}$ mice show reduced open-arm time relative to controls while other manipulations of RCAN1 overexpression did not affect open-arm time. Right columns show normal PPI of the acoustic startle response in RCAN1-overexpressing transgenic lines tested. See Materials and Methods for detailed genotype description. Dist, Distance traveled; Vel, ambulatory velocity. PPI percentage inhibition based on inhibition compared to the startle response to intertrial pulses.

ing reduced anxiety, which was restored to control levels with CsA blockade of CaN (open arm, $\chi_{(3)}^{2}=17.021, p<0.001$; closed arm, $\chi_{(3)}^{2}=15.767, p<0.001$; Fig. 5D). Post hoc comparisons of open-arm time between the groups showed significant differences between WT versus KO vehicle groups $(p=0.014)$ and between KO-CsA versus KO-vehicle groups $(p=0.004)$, while there was no difference between KO-CsA and WT-vehicle groups $(p=0.505)$ or WT-CsA groups $(p=0.995)$. A post hoc analysis also revealed no significant effect of CsA treatment on open-arm time in WT mice (WT-vehicle vs WT-CsA, $p=0.457$ ). Unlike FK506 treatment used for OFA assays, intracerebroventricular application of CsA did not induce hypoactivity in either WT or KO mice as measured by total distance traveled (Fig. 5E). Therefore, these findings combined with our OFA rescue data are consistent with the idea that enhanced $\mathrm{CaN}$ activity contributes to the reduced anxiety observed in Rcan $1 \mathrm{KO}$ mice.

\section{Rcan $1 \mathrm{KO}$ mice are resistant to the acute anxiogenic effects of} fluoxetine treatment

In patients with anxiety disorders, chronic treatment with SSRIs is frequently prescribed. There is evidence that $\mathrm{CaN}$ activity is involved in the activities of SSRIs and other psychotropic drugs (Crozatier et al., 2007; Bahi et al., 2009; Rushlow et al., 2009). Therefore, we asked whether RCAN1 plays a role in modulating SSRI-mediated effects on anxiety. EPM analysis of behavior was performed on WT and Rcan1 KO mice after either acute or chronic fluoxetine therapy. Consistent with previous reports (Belzung et al., 2001; Liu et al., 2010), 1 d after fluoxetine treatment, WT mice displayed significantly less open-arm time, reflecting increased anxiety (open arm, main effect of genotype, $F_{(1,43)}=50.168, p<0.001$; main effect of fluoxetine, $F_{(1,43)}=8.864, p<0.005$; genotype $\times$ fluoxetine, $F_{(1,43)}=0.649, p>0.4 ;$ WT-vehicle vs WT-fluoxetine, $p=0.044$; Fig. $6 A$ ). In contrast, post hoc analyses revealed that the response of fluoxetine-treated Rcan $1 \mathrm{KO}$ mice was indistinguishable from that of vehicle-treated Rcan $1 \mathrm{KO}$ mice $(p=$ 0.446 ). However, both groups of KO mice spent significantly more time in the open arms than WT mice (KO-vehicle vs WT-vehicle, $p<0.001$; KO-fluoxetine vs WT-vehicle, $p=$ 0.03 ). These effects could not be explained by locomotor differences between either genotypes or drug treatments (distance traveled: main effect of genotype, $F_{(1,43)}=0.005, p>$ 0.9 ; main effect of fluoxetine, $F_{(1,43)}=0.234, p>0.6$; genotype $\times$ fluoxetine, $\left.F_{(1,43)}=0.649, p>0.4\right)$. Post hoc comparisons of all groups revealed no significant differences in distance traveled (Fig. 6B). Together, these results support a role for RCAN1 signaling in the anxiogenic effects of acute SSRI administration.

To determine whether the lack of an anxiogenic response to fluoxetine in Rcan 1 KO mice may be due to a slower onset, we tested EPM behavior after 3 and $15 \mathrm{~d}$ of fluoxetine treatment. To control for "one-trial" effects confounding our results (File et al., 1990), we tested new cohorts of mice that had never been exposed to the EPM. We found that fluoxetine treatment affected both $\mathrm{KO}$ and WT EPM behavior in a time-dependent manner (Fig. 6C; open-arm time: main effect of genotype, $F_{(1,41)}=61.179, p<$ 
A

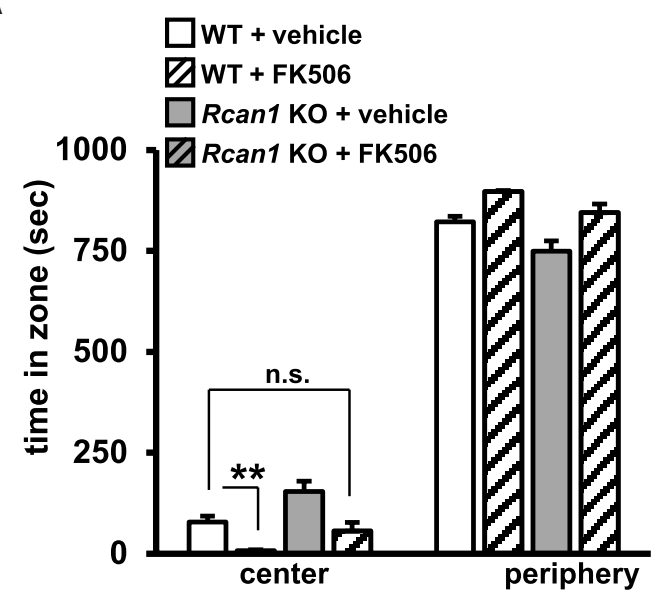

B

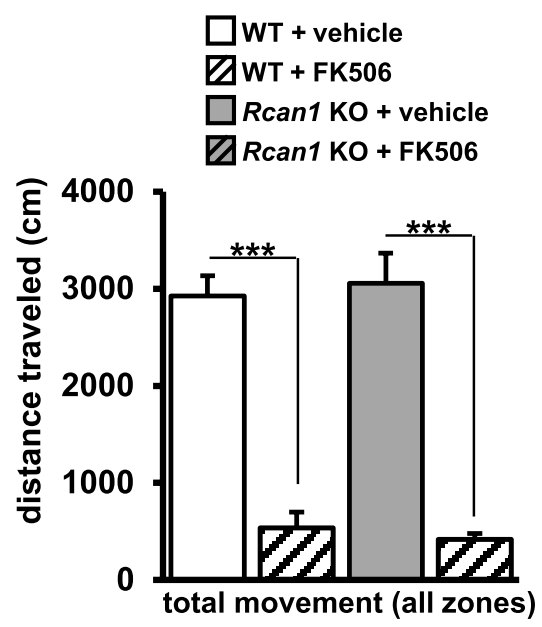

C

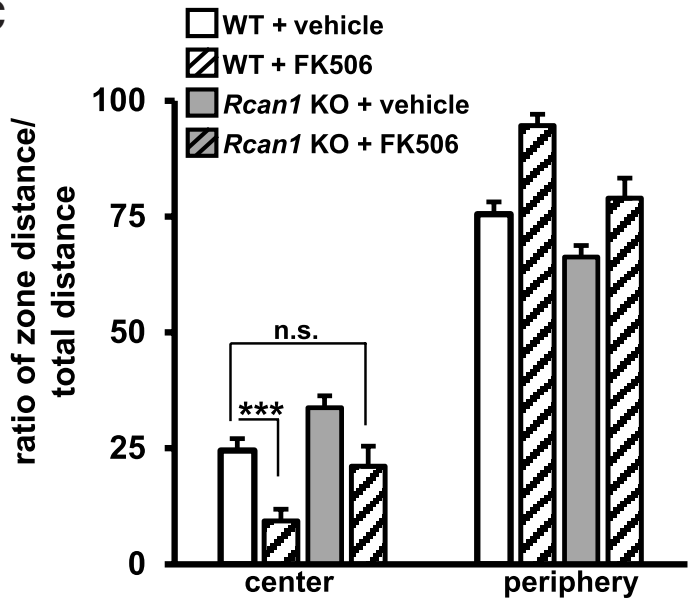

D

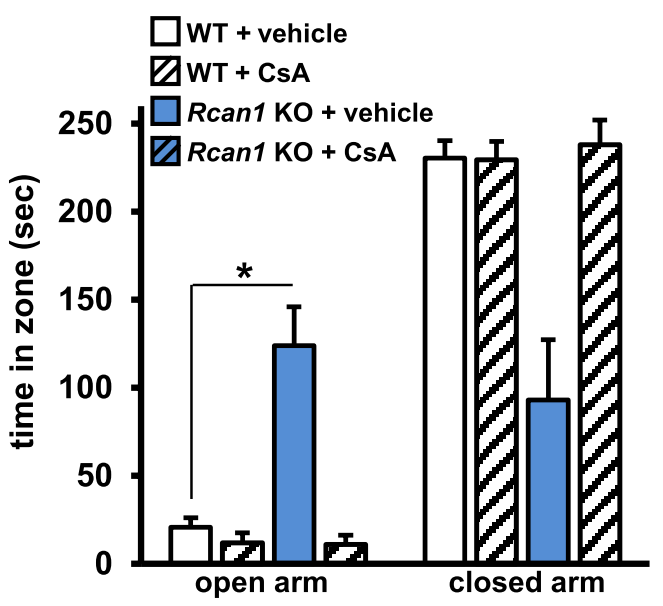

E

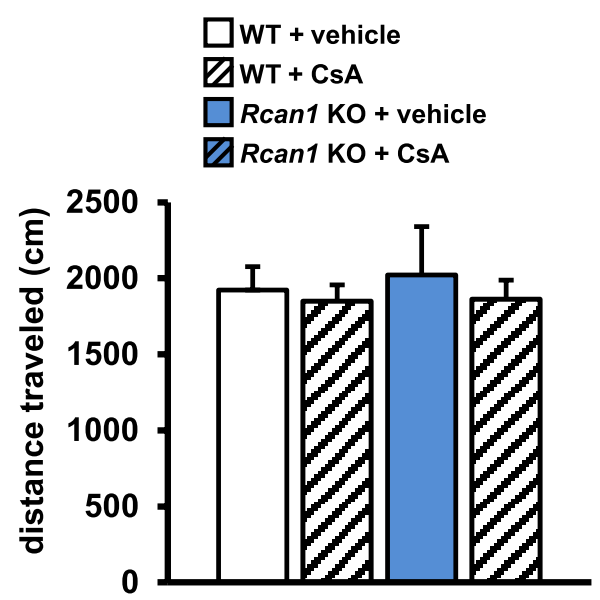

Figure 5. Acute pharmacological blockade of CaN rescues reduced anxiety in Rcan $1 \mathrm{KO}$ mice. $A$, Time in each OFA zone following intraperitoneal FK506 treatment. Vehicle-treated Rcan $1 \mathrm{KO}$ mice spend more time in the center zone than periphery of the OFA compared with similarly treated WT controls, whereas FK506-treated Rcan $1 \mathrm{KO}$ mice are not different from vehicle-treated WT controls. B, FK506 treatment reduces distance traveled by both WT and Rcan $1 \mathrm{KO}$ mice in all zones of the OFA. C, Movement in the 0FA plotted as a ratio of distance traveled in each zone (zone distance) to total distance traveled during the test period. Using this measure, vehicle-treated Rcan $1 \mathrm{KO}$ mice move significantly more than vehicle-treated WT littermates in the center zone, whereas FK506-treated KO mice are indistinguishable from vehicle-treated WT mice. D, EPM open-arm and closed-arm time following (sA treatment via intraventricular cannulation. Pairwise comparisons (Dunn's with Bonferroni) revealed significant effects between the WT and KO vehicle groups $(p=0.014)$ and between the KO CsA and vehicle treatment groups ( $p=0.004)$, while there was no difference between KO-CSA and WT-vehicle groups $(p=0.505)$ or WT-CsA groups $(p=0.995)$. Center zone measurements are not included but there is no difference between the groups. $\boldsymbol{E}$, Total distance moved in the EPM is similar for WT and Rcan $1 \mathrm{KO}$ mice following intracerebroventricular administration of CsA or vehicle. OFA: $N=12$ K0-vehicle, 20 WT-vehicle, 9 K0-FK506, 9 WT-FK506; EPM: $N=7$ KO-vehicle, 11 WT-vehicle, 7 KO-CSA, 10 WT-CSA. ${ }^{* *} p<0.01 ; * * * 00.001 ;$ n.s., $p>0.05$. 

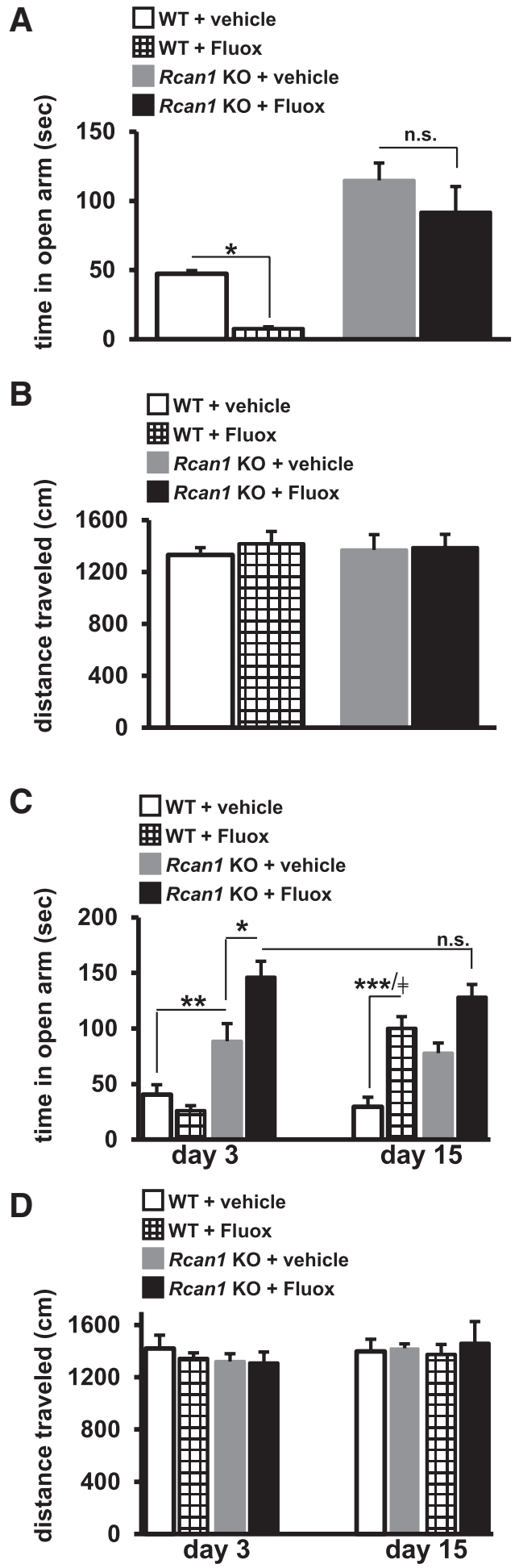

Figure 6. Rcan1 $\mathrm{KO}$ mice are resistant to the acute anxiogenic effects of SSRI administration. $A$, WT but not $R$ can $1 \mathrm{~K} 0$ mice injected with intraperitoneal fluoxetine and tested $24 \mathrm{~h}$ later in the EPM show decreased open-arm time compared with their vehicle-treated (WT or KO) cohorts, indicating increased anxiety in fluoxetine-treated WT mice. $\boldsymbol{B}$, Fluoxetine treatment does not change overall locomotor activity within or across genotypes. Total distance traveled for test period is shown. C, Open-arm time of EPM-naive mice following either 3 or $15 \mathrm{~d}$ of treatment with fluoxetine or vehicle. All animals tested had no prior experience with the EPM. Fluoxetinetreated Rcan $1 \mathrm{KO}$ mice increase time spent in the open arms, indicating reduced anxiety, compared with vehicle-treated KO mice after $3 \mathrm{~d}$ of treatment. After $15 \mathrm{~d}$ of treatment, fluoxetine-treated WT mice show a significant increase in open-arm time compared with WTvehicle controls on day 3 or 15 . Fluoxetine treatment also increased open-arm time in $R$ can $1 \mathrm{KO}$ mice on day 15 compared with vehicle treatment, but the difference did not reach statistical significance.
0.001; main effect of fluoxetine, $F_{(1,41)}=27.548, p<0.001$; main effect of day, $F_{(1,41)}=1.223, p>0.275$; day $\times$ fluoxetine, $F_{(1,41)}=$ $6.186, p=0.017$; genotype $\times$ fluoxetine, $F_{(1,41)}=2.754, p=$ 0.105 ; day $\times$ genotype $\times$ fluoxetine, $\left.F_{(1,41)}=8.813, p<0.001\right)$. On day 3 , post hoc analyses showed that fluoxetine treatment tended to decrease open-arm time (anxiogenic effect) in WT mice compared with vehicle treatment, but this difference did not reach statistical significance $(p=0.081)$. When mice were tested after $15 \mathrm{~d}$ of treatment, post hoc comparisons showed that fluoxetine-treated WT mice significantly increased open-arm time compared with vehicle-treated WT mice $(p<0.001)$ and compared with fluoxetine-treated WT mice on day $3(p<0.001)$, consistent with an anxiolytic effect of fluoxetine.

Predictably, vehicle-treated Rcan1 KO mice spent significantly more time in the EPM open arms than vehicle-treated WT mice on both day $3(p=0.006)$ and day $15(p=0.036$; Fig. $6 C)$. In contrast to the fluoxetine effects in WT mice on day 3, fluoxetine-treated Rcan1 KO mice spent more time in the open arms than vehicle-treated KO counterparts on day $3(p=0.010)$. This indicates that by day 3 of fluoxetine treatment, Rcan $1 \mathrm{KO}$ mice displayed a significant anxiolytic response, which WT mice displayed on day 15, and this response did not increase with further treatment time in $\mathrm{KO}$ mice (KO-fluoxetine day 3 vs day $15, p>0.8$; KO-vehicle day 15 vs KO-fluoxetine day $15, p=0.071$; Fig. $6 C$ ). These results were not due to fluoxetine effects on locomotor function (distance traveled: main effect of genotype, $F_{(1,41)}=0.237, p>0.6$; main effect of fluoxetine, $F_{(1,41)}=0.009, p>0.9$; main effect of day, $F_{(1,41)}=1.156, p>$ 0.2 ; genotype $\times$ fluoxetine, $F_{(1,41)}=0.279, p>0.6$; day $\times$ fluoxetine, $F_{(1,41)}=0.669, p>0.4$; day $\times$ fluoxetine $\times$ genotype, $\left.F_{(1,41)}=0.000, p>0.9\right)$. Post hoc comparisons indicated no differences in distance traveled between any of the experimental groups ( $p>0.9$ for all comparisons; Fig. 6D). These data suggest that RCAN1 increased the latency for the anxiolytic benefits from fluoxetine and provide evidence for RCAN1 regulation of SSRI-mediated anxiety effects.

\section{Discussion}

Using two behavioral paradigms for measuring unconditioned exploratory anxiety in rodents, we found that Rcan $1 \mathrm{KO}$ mice increased time spent in exposed areas, indicative of reduced anxiety. In contrast to removal of RCAN1, we observed that RCAN1overexpressing mice mildly reduced time spent in exposed areas, indicative of increased anxiety. Using genetic and pharmacological approaches, we provided evidence that CaN and CREB signaling were involved in this phenomenon. Last, we identified RCAN1 as a potential regulator of the anxiogenic effects associated with early SSRI administration.

Our study used anxiety tests that measure spontaneous responses to novel environments in which the drive to explore is counterbalanced by remaining in safe areas (Bouwknecht and Paylor, 2008). Exposing mice to a novel environment creates this unconditioned approach-avoidance conflict between motivation to explore it and "generalized fear" of novelty (Carobrez and Bertoglio, 2005). Because anxiety in rodents can frequently involve behavioral "freezing," one possible ex-

$\leftarrow$

D, Total distance moved in the EPM by all the treatment groups is similar. No difference in movement was observed in EPM-naive animals tested after 1,3, or $15 \mathrm{~d}$ of treatment. $N$ (day 1 , day 3, day 15) = (11,9,9) K0-vehicle; $(12,7,8)$ WT-vehicle; $(10,9,9)$ K0-fluoxetine; $(11,6,6)$ WT-fluoxetine. WT-fluoxetine day 3 vs WT-day 15 fluoxetine denoted by ${ }^{*} p<0.05$; ${ }^{* *} p<$ $0.01 ;{ }^{* * *}$ or $\neq p<0.001 ;$ i.s., $p>0.05$. 
planation for the increased measures of anxiety in Rcan $1 \mathrm{KO}$ mice would be changes in locomotor activity. By numerous measures, however, Rcan1 KO mice were indistinguishable from WT littermates in locomotor and basic sensorimotor function (Figs. $3 B, C, 4 C, D, 5 B, 6 B, D$ ). Given the important role of $\mathrm{CaN}$ in neuronal gene expression (Bito et al., 1996; Lam et al., 2009; Ch'ng et al., 2012), one strong possibility is that RCAN1 removal affects gene expression linked to affective behaviors in these mice.

There is abundant evidence that anxiety disorders have a strong genetic component (Schumacher et al., 2011; Yang and $\mathrm{Lu}, 2011)$. Some animals in the same cohort always measure higher (or lower) in anxiety than the others. This variability within a homogeneous group in a particular situation may result from intersubject differences in the baseline or threshold level of anxiety established by variations in gene expression during development. This inherent difference in level of anxiety-related responses may be considered a trait (Endler and Kocovski, 2001; Elwood et al., 2012). In this study, developmental manipulations of Rcan1 signaling had affected the expression of innate anxiety (Figs. 3-5), whereas postdevelopmental manipulations had no detectable effect on anxiety (Fig. $4 F$ ). This suggests that RCAN1 plays a role in establishing innate or trait-based anxiety levels. Further support for this notion is derived from our biochemical data. The enhanced CREB activation in several brain regions of Rcan $1 \mathrm{KO}$ mice strongly suggests an epigenetic component, or altered gene expression via histone modification, in the display of reduced anxiety in these mice (Fig. 1B). Moreover, our data showing enhanced BDNF expression suggests that a target population of CREB-dependent genes is involved in establishing trait-based aspects of anxiety (Fig. 1D). While our results in combination with those of previous studies suggest that RCAN1/CaN signaling operates through CREB and $\mathrm{BDNF}$ to regulate innate anxiety, it is possible that the anxietyrelated behaviors we observe in Rcan $1 \mathrm{KO}$ mice are mediated through other downstream effectors. This important issue can be addressed in future studies by selectively targeting CREB activity and its transcriptional targets in the context of altered RCAN1 signaling. Together, these findings may be important in neurodevelopmental disorders, such as Down syndrome, that overexpress RCAN1 and are associated with anxiety disorders (Myers and Pueschel, 1991).

Because multiple neuronal circuits are involved in the display of anxiety, subtle differences in the regional or total overexpression levels of RCAN1 between the Cre driver lines or RCAN1 transgenic lines may also contribute to the effects we observed on anxiety. Indeed, we do observe differences in transgenic RCAN1 expression between the two Cre lines (Fig. $4 E$ ). Although the Nse-Cre and CamkII $\alpha$-Cre driver lines used in this study express in largely overlapping cell and regional populations (Forss-Petter et al., 1990; Tsien et al., 1996; Hoeffer et al., 2008), we did find that not all developmental manipulations of RCAN1 affected our measures of anxiety. It is possible that RCAN1/CaN activity at different levels in different brain regions and developmental time points exerts varying control over the display of anxiety. In future studies, this will be an important issue to clarify, approached perhaps by using spatially and temporally restricted removal of Rcan1 in the brain or pharmacological disruption of RCAN1CaN interaction in vivo.

Interestingly, acute systemic inhibition of CaN activity reversed the reduced anxiety (Fig. 5) and downregulated the enhanced CREB phosphorylation (Fig. 1C) we observed in Rcan1 $\mathrm{KO}$ mice. These results indicate that Rcan $1 \mathrm{KO}$ mice are not developmentally or genetically inflexible but maintain a range of responsiveness to contextual anxiogenic stimuli. Experience and environmental context are powerful modulating factors that can increase or decrease the expression of anxiety, with novel or exposed environments eliciting higher displays of anxiety-related behaviors (Endler and Kocovski, 2001). It may be that RCAN1/ $\mathrm{CaN}$ signaling during development is involved in establishing innate anxiety levels and acute modulation of CaN activity affects context-dependent or state-based displays of anxiety. Mechanistically, this could be explained by RCAN1/CaN signaling acting in different cellular compartments. In the regulation of innate anxiety, RCAN1/CaN signaling may alter gene expression via CREB. In anxiety expression affected more strongly by context, RCAN1/CaN may act on channels/receptors, such as GluA and $\mathrm{GABA}_{\mathrm{A}}$ receptors, to regulate cell surface levels or functional properties. Indeed, we provide biochemical evidence in support of compartmental RCAN1/ CaN signaling (Fig. 2). Another possible explanation is that RCAN1/CaN signaling in different neuronal circuits exerts varying control over the display of anxiety and responsiveness to acute systemic CaN blockade. Future studies using chronic CaN blockade in Rcan $1 \mathrm{KO}$ mice, regional disruption of CREB signaling, or compartment-directed disruption of RCAN1/ CaN signaling could address these ideas.

The role of RCAN1 in CaN regulation is complex but is now generally accepted to both inhibit and facilitate $\mathrm{CaN}$ activity (Kingsbury and Cunningham, 2000; Vega et al., 2003; Hilioti et al., 2004; Sanna et al., 2006; Hoeffer et al., 2007). We previously provided evidence that in the hippocampus RCAN1 functioned largely as a negative regulator of CaN activity (Hoeffer et al., 2007). Our current data suggest that with respect to CREB, RCAN1 may be a positive regulator of CaN activity, as we clearly observe increased phosphorylation of CREB in several brain regions of Rcan $1 \mathrm{KO}$ mice (Fig. 1B). Previous studies have shown that $\mathrm{CaN}$ acts to negatively regulate CREB phosphorylation (Bito et al., 1996; Chang and Berg, 2001; Hongpaisan et al., 2003). However, these studies relied on cell culture while we used tissue obtained from fully developed adult brains. In addition, these earlier studies examined CaN regulation of CREB following transient pharmacological blockade. Other studies examining CREB activity under conditions of chronically increased $\mathrm{CaN}$ activity have demonstrated enhanced CREB phosphorylation (Kingsbury et al., 2007), which is consistent with what we observed in Rcan 1 KO mice (Fig. 1). Thus, CaN regulation of CREB activity may also occur by indirect means, such as, for example, as our data suggest, through cellular trafficking of $\mathrm{CaN}$ and its target substrates (Fig. 2). Chronically elevated CaN activity may result in CREB regulation that is inherently different from what is observed following transient manipulations of CaN activity or in developmentally WT tissues.

Several lines of evidence point to a prominent role for $\mathrm{CaN}$ in psychophysiological disorders involving anxiety, such as schizophrenia (Pallanti et al., 2013), and responses to antianxiety medication. CaN expression is reduced in schizophrenia patients (Gerber et al., 2003) and reduced CaN expression is associated with schizophrenia-like symptoms in mouse models (Miyakawa et al., 2003). Psychosocial stress also has been shown to downregulate forebrain CaN levels (Gerges et al., 2003). The phosphorylation of DARPP 32 , a CaN target, is altered in the limbic and cortical regions that control emotional states after psychotropic medications (Svenningsson et al., 2003). Finally, chronic treatment with the SSRI fluoxetine 
has been shown to elevate CaN expression in rodents (Crozatier et al., 2007).

SSRIs are initially anxiogenic in human patients (Den Boer and Westenberg, 1990; Jick et al., 2004; Grillon et al., 2007). This observation, coupled with the slow onset of therapeutic benefits, often results in disappointing clinical outcomes with SSRI treatments of anxiety disorders (Baldwin and Tiwari, 2009) and in extreme cases can increase suicide risk in adolescents (Jick et al., 2004; Olfson et al., 2006). Importantly, we found that removal of RCAN1 blocked the acute anxiogenic response to fluoxetine during the early phases of chronic treatment (Fig. 6A). Furthermore, removal of RCAN1 decreased the onset for the anxiolytic effects of fluoxetine; Rcan $1 \mathrm{KO}$ mice showed a significant improvement in EPM open-arm time, indicating reduced anxiety, very shortly after fluoxetine administration (day 3; Fig. 6C) compared with WT mice. These data fit well with the observation that chronic CaN overexpression enhances responsiveness to antidepressants (Crozatier et al., 2007). We also found enhanced BDNF levels in Rcan1 KO mice, which is consistent with a previous report of a decreased response to fluoxetine in mice with a BDNF mutation (val66met) that is associated with decreased BDNF release and with increased depression in humans (Chen et al., 2006). The identification of RCAN $1 / \mathrm{CaN}$ signaling in the paradoxical response to SSRI treatment may provide new therapeutic avenues to ameliorating anxiogenic side effects and improving latency times during SSRI treatment.

In closing, our study has identified for the first time a link between RCAN1 function and the display of anxiety. Importantly, we also show that inhibition of RCAN1 signaling can occlude the acute paradoxical anxiogenic effects of SSRI administration. Despite the wide variety of compounds available for the treatment of anxiety, little is known about the alterations in molecular signaling that follow from their use. Identifying and characterizing effector pathways such as RCAN1/ CaN can provide valuable targets for predicting diagnostic efficacy, assessing risk for tolerance and abuse, and preventing adverse effects of SSRI use.

\section{References}

Alberts AS, Montminy M, Shenolikar S, Feramisco JR (1994) Expression of a peptide inhibitor of protein phosphatase 1 increases phosphorylation and activity of CREB in NIH 3T3 fibroblasts. Mol Cell Biol 14:4398-4407. Medline

Bahi A, Mineur YS, Picciotto MR (2009) Blockade of protein phosphatase $2 \mathrm{~B}$ activity in the amygdala increases anxiety- and depression-like behaviors in mice. Biol Psychiatry 66:1139-1146. CrossRef Medline

Baldwin DS, Tiwari N (2009) The pharmacologic treatment of patients with generalized anxiety disorder: where are we now and where are we going? CNS Spectr 14:5-12. Medline

Barrot M, Olivier JD, Perrotti LI, DiLeone RJ, Berton O, Eisch AJ, Impey S, Storm DR, Neve RL, Yin JC, Zachariou V, Nestler EJ (2002) CREB activity in the nucleus accumbens shell controls gating of behavioral responses to emotional stimuli. Proc Natl Acad Sci U S A 99:11435-11440. CrossRef Medline

Baumgärtel K, Mansuy IM (2012) Neural functions of calcineurin in synaptic plasticity and memory. Learn Mem 19:375-384. CrossRef Medline

Belzung C, Le Guisquet AM, Barreau S, Calatayud F (2001) An investigation of the mechanisms responsible for acute fluoxetine-induced anxiogenic-like effects in mice. Behav Pharmacol 12:151-162. CrossRef Medline

Bito H, Deisseroth K, Tsien RW (1996) CREB phosphorylation and dephosphorylation: a $\mathrm{Ca}(2+)$ - and stimulus duration-dependent switch for hippocampal gene expression. Cell 87:1203-1214. CrossRef Medline
Bouwknecht JA, Paylor R (2008) Pitfalls in the interpretation of genetic and pharmacological effects on anxiety-like behaviour in rodents. Behav Pharmacol 19:385-402. CrossRef Medline

Carlezon WA Jr, Duman RS, Nestler EJ (2005) The many faces of CREB. Trends Neurosci 28:436-445. CrossRef Medline

Carme Mulero M, Orzáez M, Messeguer J, Messeguer A, Pérez-Payá E, PérezRiba M (2010) A fluorescent polarization-based assay for the identification of disruptors of the RCAN1-calcineurin A protein complex. Anal Biochem 398:99-103. CrossRef Medline

Carobrez AP, Bertoglio LJ (2005) Ethological and temporal analyses of anxiety-like behavior: the elevated plus-maze model 20 years on. Neurosci Biobehav Rev 29:1193-1205. CrossRef Medline

Chan B, Greenan G, McKeon F, Ellenberger T (2005) Identification of a peptide fragment of DSCR1 that competitively inhibits calcineurin activity in vitro and in vivo. Proc Natl Acad Sci U S A 102:13075-13080. CrossRef Medline

Chang KT, Berg DK (2001) Voltage-gated channels block nicotinic regulation of CREB phosphorylation and gene expression in neurons. Neuron 32:855-865. CrossRef Medline

Chen ZY, Jing D, Bath KG, Ieraci A, Khan T, Siao CJ, Herrera DG, Toth M, Yang C, McEwen BS, Hempstead BL, Lee FS (2006) Genetic variant BDNF (Val66Met) polymorphism alters anxiety-related behavior. Science 314:140-143. CrossRef Medline

Ch'ng TH, Uzgil B, Lin P, Avliyakulov NK, O’Dell TJ, Martin KC (2012) Activity-dependent transport of the transcriptional coactivator CRTC1 from synapse to nucleus. Cell 150:207-221. CrossRef Medline

Crozatier C, Farley S, Mansuy IM, Dumas S, Giros B, Tzavara ET (2007) Calcineurin (protein phosphatase $2 \mathrm{~B}$ ) is involved in the mechanisms of action of antidepressants. Neuroscience 144:1470-1476. CrossRef Medline

Deacon RM, Penny C, Rawlins JN (2003) Effects of medial prefrontal cortex cytotoxic lesions in mice. Behav Brain Res 139:139-155. CrossRef Medline

Den Boer JA, Westenberg HG (1990) Serotonin function in panic disorder: a double blind placebo controlled study with fluvoxamine and ritanserin. Psychopharmacology (Berl) 102:85-94. CrossRef Medline

Duman CH, Duman RS (2005) Neurobiology and treatment of anxiety: signal transduction and neural plasticity. Handb Exp Pharmacol 305-334. Medline

Elwood LS, Wolitzky-Taylor K, Olatunji BO (2012) Measurement of anxious traits: a contemporary review and synthesis. Anxiety Stress Coping 25:647-666. CrossRef Medline

Endler NS, Kocovski NL (2001) State and trait anxiety revisited. J Anxiety Disord 15:231-245. CrossRef Medline

Fayard B, Loeffler S, Weis J, Vögelin E, Krüttgen A (2005) The secreted brain-derived neurotrophic factor precursor pro-BDNF binds to TrkB and p75NTR but not to TrkA or TrkC. J Neurosci Res 80:18-28. CrossRef Medline

File SE, Mabbutt PS, Hitchcott PK (1990) Characterisation of the phenomenon of "one-trial tolerance" to the anxiolytic effect of chlordiazepoxide in the elevated plus-maze. Psychopharmacology (Berl) 102:98-101. CrossRef Medline

Finkbeiner S, Tavazoie SF, Maloratsky A, Jacobs KM, Harris KM, Greenberg ME (1997) CREB: a major mediator of neuronal neurotrophin responses. Neuron 19:1031-1047. CrossRef Medline

Forss-Petter S, Danielson PE, Catsicas S, Battenberg E, Price J, Nerenberg M, Sutcliffe JG (1990) Transgenic mice expressing beta-galactosidase in mature neurons under neuron-specific enolase promoter control. Neuron 5:187-197. CrossRef Medline

Frielingsdorf H, Bath KG, Soliman F, Difede J, Casey BJ, Lee FS (2010) Variant brain-derived neurotrophic factor Val66Met endophenotypes: implications for posttraumatic stress disorder. Ann N Y Acad Sci 1208:150-157. CrossRef Medline

Garcia R, Vouimba RM, Baudry M, Thompson RF (1999) The amygdala modulates prefrontal cortex activity relative to conditioned fear. Nature 402:294-296. CrossRef Medline

Genoux D, Haditsch U, Knobloch M, Michalon A, Storm D, Mansuy IM (2002) Protein phosphatase 1 is a molecular constraint on learning and memory. Nature 418:970-975. CrossRef Medline

Gerber DJ, Hall D, Miyakawa T, Demars S, Gogos JA, Karayiorgou M, Tonegawa S (2003) Evidence for association of schizophrenia with genetic variation in the $8 \mathrm{p} 21.3$ gene, PPP3CC, encoding the calcineu- 
rin gamma subunit. Proc Natl Acad Sci U S A 100:8993-8998. CrossRef Medline

Gerges NZ, Aleisa AM, Schwarz LA, Alkadhi KA (2003) Chronic psychosocial stress decreases calcineurin in the dentate gyrus: a possible mechanism for preservation of early ltp. Neuroscience 117:869-874. CrossRef Medline

Gould TD, ed (2009) Mood and anxiety related phenotypes in mice. Characterizing using behavioral tests. Saskatoon, SK, Canada: Humana.

Grillon C, Levenson J, Pine DS (2007) A single dose of the selective serotonin reuptake inhibitor citalopram exacerbates anxiety in humans: a fear-potentiated startle study. Neuropsychopharmacology 32:225-231. CrossRef Medline

Hilioti Z, Gallagher DA, Low-Nam ST, Ramaswamy P, Gajer P, Kingsbury TJ, Birchwood CJ, Levchenko A, Cunningham KW (2004) GSK-3 kinases enhance calcineurin signaling by phosphorylation of RCNs. Genes Dev 18:35-47. CrossRef Medline

Hoeffer CA, Dey A, Sachan N, Wong H, Patterson RJ, Shelton JM, Richardson JA, Klann E, Rothermel BA (2007) The Down syndrome critical region protein RCAN1 regulates long-term potentiation and memory via inhibition of phosphatase signaling. J Neurosci 27:1316113172. CrossRef Medline

Hoeffer CA, Tang W, Wong H, Santillan A, Patterson RJ, Martinez LA, Tejada-Simon MV, Paylor R, Hamilton SL, Klann E (2008) Removal of FKBP12 enhances mTOR-Raptor interactions, LTP, memory, and perseverative/repetitive behavior. Neuron 60:832-845. CrossRef Medline

Hongpaisan J, Winters CA, Andrews SB (2003) Calcium-dependent mitochondrial superoxide modulates nuclear CREB phosphorylation in hippocampal neurons. Mol Cell Neurosci 24:1103-1115. CrossRef Medline

Jiang X, Xu K, Hoberman J, Tian F, Marko AJ, Waheed JF, Harris CR, Marini AM, Enoch MA, Lipsky RH (2005) BDNF variation and mood disorders: a novel functional promoter polymorphism and Val66Met are associated with anxiety but have opposing effects. Neuropsychopharmacology 30:1353-1361. Medline

Jick H, Kaye JA, Jick SS (2004) Antidepressants and the risk of suicidal behaviors. JAMA 292:338-343. CrossRef Medline

Kingsbury TJ, Cunningham KW (2000) A conserved family of calcineurin regulators. Genes Dev 14:1595-1604. Medline

Kingsbury TJ, Bambrick LL, Roby CD, Krueger BK (2007) Calcineurin activity is required for depolarization-induced, CREB-dependent gene transcription in cortical neurons. J Neurochem 103:761-770. CrossRef Medline

Lam BY, Zhang W, Enticknap N, Haggis E, Cader MZ, Chawla S (2009) Inverse regulation of plasticity-related immediate early genes by calcineurin in hippocampal neurons. J Biol Chem 284:12562-12571. CrossRef Medline

Liotti M, Mayberg HS, Brannan SK, McGinnis S, Jerabek P, Fox PT (2000) Differential limbic-cortical correlates of sadness and anxiety in healthy subjects: implications for affective disorders. Biol Psychiatry 48:30-42. CrossRef Medline

Liu FC, Graybiel AM (1996) Spatiotemporal dynamics of CREB phosphorylation: transient versus sustained phosphorylation in the developing striatum. Neuron 17:1133-1144. CrossRef Medline

Liu J, Garza JC, Bronner J, Kim CS, Zhang W, Lu XY (2010) Acute administration of leptin produces anxiolytic-like effects: a comparison with fluoxetine. Psychopharmacology (Berl) 207:535-545. CrossRef

Liu Q, Busby JC, Molkentin JD (2009) Interaction between TAK1-TAB1TAB2 and RCAN1-calcineurin defines a signalling nodal control point. Nat Cell Biol 11:154-161. CrossRef Medline

Ludewig S, Ludewig K, Geyer MA, Hell D, Vollenweider FX (2002) Prepulse inhibition deficits in patients with panic disorder. Depress Anxiety 15:5560. CrossRef Medline

Manji HK, Gottesman II, Gould TD (2003) Signal transduction and genesto-behaviors pathways in psychiatric diseases. Science's STKE: signal transduction knowledge environment 2003:pe49. Medline

Mantamadiotis T, Lemberger T, Bleckmann SC, Kern H, Kretz O, Martin Villalba A, Tronche F, Kellendonk C, Gau D, Kapfhammer J, Otto C, Schmid W, Schütz G (2002) Disruption of CREB function in brain leads to neurodegeneration. Nat Genet 31:47-54. CrossRef Medline

Martínez-Martínez S, Genescà L, Rodríguez A, Raya A, Salichs E, Were F, López-Maderuelo MD, Redondo JM, de la Luna S (2009) The RCAN carboxyl end mediates calcineurin docking-dependent inhibition via a site that dictates binding to substrates and regulators. Proc Natl Acad Sci U S A 106:6117-6122. CrossRef Medline

Martinowich K, Hattori D, Wu H, Fouse S, He F, Hu Y, Fan G, Sun YE (2003) DNA methylation-related chromatin remodeling in activity-dependent BDNF gene regulation. Science 302:890-893. CrossRef Medline

Miyakawa T, Leiter LM, Gerber DJ, Gainetdinov RR, Sotnikova TD, Zeng H, Caron MG, Tonegawa S (2003) Conditional calcineurin knockout mice exhibit multiple abnormal behaviors related to schizophrenia. Proc Natl Acad Sci U S A 100:8987-8992. CrossRef Medline

Molendijk ML, van Tol MJ, Penninx BW, van der Wee NJ, Aleman A, Veltman DJ, Spinhoven P, Elzinga BM (2012) BDNF val66met affects hippocampal volume and emotion-related hippocampal memory activity. Transl Psychiatry 2:e74. CrossRef Medline

Myers BA, Pueschel SM (1991) Psychiatric disorders in persons with Down syndrome. J Nerv Ment Dis 179:609-613. CrossRef Medline

Myers-Schulz B, Koenigs M (2012) Functional anatomy of ventromedial prefrontal cortex: implications for mood and anxiety disorders. Mol Psychiatry 17:132-141. CrossRef Medline

Oh M, Rybkin II, Copeland V, Czubryt MP, Shelton JM, van Rooij E, Richardson JA, Hill JA, De Windt LJ, Bassel-Duby R, Olson EN, Rothermel BA (2005) Calcineurin is necessary for the maintenance but not embryonic development of slow muscle fibers. Mol Cell Biol 25:6629-6638. CrossRef Medline

Olfson M, Marcus SC, Shaffer D (2006) Antidepressant drug therapy and suicide in severely depressed children and adults: a case-control study. Arch Gen Psychiatry 63:865-872. CrossRef Medline

Pallanti S, Cantisani A, Grassi G (2013) Anxiety as a core aspect of schizophrenia. Curr Psychiatry Rep 15:354. CrossRef Medline

Pandey SC, Zhang D, Mittal N, Nayyar D (1999) Potential role of the gene transcription factor cyclic AMP-responsive element binding protein in ethanol withdrawal-related anxiety. J Pharmacol Exp Ther 288:866-878. Medline

Rakofsky JJ, Ressler KJ, Dunlop BW (2012) BDNF function as a potential mediator of bipolar disorder and post-traumatic stress disorder comorbidity. Mol Psychiatry 17:22-35. CrossRef Medline

Rios M, Fan G, Fekete C, Kelly J, Bates B, Kuehn R, Lechan RM, Jaenisch R (2001) Conditional deletion of brain-derived neurotrophic factor in the postnatal brain leads to obesity and hyperactivity. Mol Endocrinol 15: 1748-1757. CrossRef Medline

Rothermel BA, Vega RB, Williams RS (2003) The role of modulatory calcineurin-interacting proteins in calcineurin signaling. Trends Cardiovasc Med 13:15-21. CrossRef Medline

Rothermel B, Vega RB, Yang J, Wu H, Bassel-Duby R, Williams RS (2000) A protein encoded within the Down syndrome critical region is enriched in striated muscles and inhibits calcineurin signaling. J Biol Chem 275: 8719-8725. CrossRef Medline

Rushlow WJ, Seah C, Sutton LP, Bjelica A, Rajakumar N (2009) Antipsychotics affect multiple calcium calmodulin dependent proteins. Neuroscience 161:877-886. CrossRef Medline

Sanna B, Brandt EB, Kaiser RA, Pfluger P, Witt SA, Kimball TR, van Rooij E, De Windt LJ, Rothenberg ME, Tschop MH, Benoit SC, Molkentin JD (2006) Modulatory calcineurin-interacting proteins 1 and 2 function as calcineurin facilitators in vivo. Proc Natl Acad Sci U S A 103:7327-7332. CrossRef Medline

Schumacher J, Kristensen AS, Wendland JR, Nöthen MM, Mors O, McMahon FJ (2011) The genetics of panic disorder. J Med Genet 48:361-368. CrossRef Medline

Serkova N, Hausen B, Berry GJ, Jacobsen W, Benet LZ, Morris RE, Christians U (2000) Tissue distribution and clinical monitoring of the novel macrolide immunosuppressant SDZ-RAD and its metabolites in monkey lung transplant recipients: interaction with cyclosporine. J Pharmacol Exp Ther 294:323-332. Medline

Serkova N, Jacobsen W, Niemann CU, Litt L, Benet LZ, Leibfritz D, Christians U (2001) Sirolimus, but not the structurally related RAD (everolimus), enhances the negative effects of cyclosporine on mitochondrial metabolism in the rat brain. Br J Pharmacol 133:875-885. CrossRef Medline

Svenningsson P, Tzavara ET, Carruthers R, Rachleff I, Wattler S, Nehls M, McKinzie DL, Fienberg AA, Nomikos GG, Greengard P (2003) Diverse psychotomimetics act through a common signaling pathway. Science 302: 1412-1415. CrossRef Medline 
Tao X, Finkbeiner S, Arnold DB, Shaywitz AJ, Greenberg ME (1998) $\mathrm{Ca}^{2+}$ influx regulates BDNF transcription by a CREB family transcription factordependent mechanism. Neuron 20:709-726. CrossRef Medline

Tsien JZ, Chen DF, Gerber D, Tom C, Mercer EH, Anderson DJ, Mayford M, Kandel ER, Tonegawa S (1996) Subregion- and cell type-restricted gene knockout in mouse brain. Cell 87:1317-1326. CrossRef Medline

Vega RB, Yang J, Rothermel BA, Bassel-Duby R, Williams RS (2002) Multiple domains of MCIP1 contribute to inhibition of calcineurin activity. J Biol Chem 277:30401-30407. CrossRef Medline

Vega RB, Rothermel BA, Weinheimer CJ, Kovacs A, Naseem RH, BasselDuby R, Williams RS, Olson EN (2003) Dual roles of modulatory calcineurin-interacting protein 1 in cardiac hypertrophy. Proc Natl Acad Sci U S A 100:669-674. CrossRef Medline
Wallace DL, Han MH, Graham DL, Green TA, Vialou V, Iñiguez SD, Cao JL, Kirk A, Chakravarty S, Kumar A, Krishnan V, Neve RL, Cooper DC, Bolaños CA, Barrot M, McClung CA, Nestler EJ (2009) CREB regulation of nucleus accumbens excitability mediates social isolationinduced behavioral deficits. Nat Neurosci 12:200-209. CrossRef Medline

Wall PM, Messier C (2000) Concurrent modulation of anxiety and memory. Behav Brain Res 109:229-241. CrossRef Medline

Wu LJ, Kim SS, Zhuo M (2008) Molecular targets of anxiety: from membrane to nucleus. Neurochem Res 33:1925-1932. CrossRef Medline

Yang XW, Lu XH (2011) Molecular and cellular basis of obsessivecompulsive disorder-like behaviors: emerging view from mouse models. Curr Opin Neurol 24:114-118. CrossRef Medline 